\title{
FACULTADES Y DERECHOS COMPARTIDOS RESPECTO DE LOS HIJOS: UNA MIRADA DESDE EL DERECHO COMPARADO*
}

\author{
RODRIGO BARCIA LEHMANN**
}

RESUMEN: Los ordenamientos jurídicos han evolucionado desde sistemas que asignaban facultades y derechos de forma exclusiva a uno de los padres, conforme al interés superior del niño a sistemas que establecen como regla general facultades y derechos compartidos. Ello ha llevado a expulsar de los diferentes sistemas jurídicos la regla de la preferencia materna y a establecer mecanismos que, en un plano de igualdad, les permitan a los padres, a pesar de su separación, participar activamente en el desarrollo de sus hijos. Nuestro sistema jurídico, como está diseñado en la actualidad, impide que se puedan establecer facultades y derechos de común acuerdo entre los padres a través por ejemplo de la distribución de las funciones del cuidado personal o de la autoridad parental. Frente a este despropósito, la Reforma que se discute actualmente en el Congreso sobre cuidado personal es un avance significativo hacia un sistema de facultades y derechos compartidos entre padres separados respecto de sus hijos; sin embargo, la Reforma no establece, a lo menos de forma expresa, la posibilidad que el juez decrete el cuidado personal compartido con oposición de uno de los padres.

PALABRAS CLAVE: Facultades y derechos de filiación compartidos regla de la preferencia materna - Cuidado compartido

\footnotetext{
* Fecha de recepción: 24 de diciembre de 2012

Fecha de aceptación: 3 de junio de 2013

Le agradezca tanto a Carolina Riveros como a Ángela Arenas su valiosa ayuda en la discusión del presente texto.

** Abogado, doctor en Derecho Civil por la Universidad Complutense de Madrid y Profesor Investigador de la Facultad de Derecho de la Universidad Finis Terrae. correo electrónico: rbarcia@uft.cl.

ABREVIATURAS: $A P=$ Audiencia Provincial [España; $] B G B=$ BürgerlichesGesetzbuch [Código Civil alemán]; $C C C h=$ Código Civil chileno; $C C E$ = Código Civil español; CodiceCivile $=$ Código Civil italiano [1942]; CIADH = Corte Interamericana de Derechos; CPE = Constitución Política del Estado [Chile]; $C A=$ Corte de Apelación; $C S=$ Corte Suprema; INSEE = Institutnational de la statique et des étudeséconomiques; LF = Ley de Filiación (Ley No 19.585/1998); LMC = Ley de Matrimonio Civil (Ley No 19.947/2004); LTF = Ley de Tribunales de Familia (Ley No 19.968/2004); LPM = Ley de Protección de Menores (Ley No 16.618/2000); $R U$ = Reino Unido; $T C=$ Tribunal Constitucional; $T E D H=$ Tribunal Europeo de Derechos Humanos; $T F=$ Tribunales de Familia; $T S=$ Tribunal Supremo espańol (equivalente a nuestra Corte Suprema) y $V I F=$ Violencia Intrafamiliar.
} 


\title{
POWERS AND JOINT CUSTODY RESPECT TO CHILDREN: A COMPARATIVE LAW PERSPECTIVE
}

\begin{abstract}
The legal systems have evolved from powers and rights assigned exclusively to one parent related to the best interest of the child to establish as a general rule to share powers and rights. It has led to the expulsion of the different legal systems the maternal preference and to establish mechanisms that in an equal way, it will allow fathers, despite their separation, to participate in the development of their children actively. Our legal system, as designed at present, does not allow to establish powers and rights by agreement between the parents, for instance the functions of personal care or parental authority. In accordance to this nonsense, the Reform that is currently being discussed in Congress about personal care is a significant step towards a system of shared powers and rights between separated parents, however, the Reformation does not establish in an open way the possibility that the judge decreed personal care with opposition of one of the parents.
\end{abstract}

KEY WORDS: powers and shared affiliation rights - maternal preference rule - joint custody.

\section{INTRODUCCIÓN}

El presente trabajo tiene como objetivo contraponer el sistema de asignación de facultades y derechos de filiación, establecido en el Derecho chileno, con el que impera en la casi totalidad de los ordenamientos jurídicos que nos suelen servir de referencia ${ }^{1}$. El análisis se centra en los casos de conflicto entre los padres, es decir, en los casos de conflicto entre los padres, como demanda de cuidado personal, y de separación judicial, nulidad y divorcio, y se hace cargo de la forma en que el Derecho comparado ha integrado el principio de igualdad o no discriminación de los padres dentro del principio del interés superior del nińo. El presente estudio, como es natural, también se hace cargo, pero de forma tangencial,

La referencia a facultades y derechos intenta poner de relieve un aspecto que se ha dejado de lado en el Derecho chileno, que se ha centrado en las relaciones de filiación en su contenido de deber y obligación. Así, la mayoría de nuestra dogmática no ha abordado al Derecho de la Infancia como facultades y derechos, que naturalmente deben tener los padres con relación a sus hijos, desde un prisma que interrelacione los principios de igualdad de los padres y del interés superior del niño. Ello se puede evidenciar desde que la dogmática chilena comprendió desde temprano que los deberes y obligaciones, que se desprenden de la filiación, son conjuntos, pero jamás se planteó la filiación como un haz de derechos y facultades conjuntas de los padres. 


\section{del Proyecto de Reforma que se está tramitando en el Congreso sobre cui- dado personal, desde que dicho Proyecto puede ser modificado.}

Se recurre al Derecho comparado por cuanto muchos de los ordenamientos jurídicos que se han analizado han evolucionaron desde sistemas de asignación exclusiva o unilateral -como el nuestro-, hacia sistemas de contrapeso de facultades y derechos entre los padres². Esta tendencia se

En realidad, el Derecho de la Infancia en una primera fase se construyó sobre la tensión entre las facultades y derechos del padre custodio y del no custodio, con relación al bienestar de los hijos. Pero, esta tendencia, que parece crucial en torno al Derecho chileno, ha sido abandonada por una posición más moderna que asimila la igualdad de los padres dentro del interés superior del niño. De hecho la tensión entre las facultades y derechos del padre custodio y no custodia está tan resuelta en el Derecho comparado ya hace tantos años, que en la actualidad se analizan otros problemas. Entre ellos, tal vez el que está más relacionado con lo planteado, en el presente trabajo, es el relativo a los derechos de las personas que no son padres, ni parientes de un nińo o adolescente, pero que han ejercido derechos parentales. En Francia este derecho de este tercero, como destaca Ruz, es reconocido por la jurisprudencia francesa. Este problema se ha presentado tanto respecto de parejas hetero como homosexuales. Sin embargo, en el caso de parejas homosexuales estos casos van asociados con la calificación de tercero, sobre todo como madre. Ruz se refiere a varias sentencias de los tribunales franceses. Entre ellos está el de una pareja de lesbianas en que la madre biológica, de acuerdo con su pareja, deciden formar una familia y al efecto celebran un acuerdo de vida en común, incluyendo un convenio de adopción aprobado por los tribunales americanos, respecto de un hijo biológico de una de ellas. La pareja, después de varios años, se separa y la conviviente solicita un régimen de residencia alternado, una semana cada dos, y en subsidio, solicita un régimen de visitas bastante amplio respecto del menor. El Tribunal de Gran Instancia de Briey, por sentencia de 21 de julio del 2010, rechazó el régimen de residencia solicitado por la demandante, pero concedió un amplio régimen de visita. Los sustentos del fallo fueron la existencia de una $<<$ familia sociológica $>$ y el interés superior del niño, estableciendo deberes para la demandante y facultades y derechos conjuntos. Ruz se refiere a otro caso, esta vez dictado por la Primera Sala de la Corte de Casación francesa, de 8 de julio del 2010. La sentencia del más alto tribunal de Francia revoca una sentencia de la Corte de Apelación de París, por la que no se reconoce un acuerdo de ejercicio de autoridad parental conjunto de dos mujeres del mismo sexo. La Corte de Casación falla a favor de la validez del acuerdo.

En Canadá se está comenzando a producir el mismo fenómeno, pero con un grado mayor de incertidumbre. Así, Rogerson nos señala que "[s]ince the introduction of the guidelines in May of 1997, (hay nota al pie) there have been a significant number of litigated cases dealing with issues relating to step-parent liability for support. Practitioners dealing with such cases are faced with an uncertain and unpredictable body of case law, but one which raises the possibility, depending upon the discretion of the court and the circumstances of the case, of the imposition of fairly extensive financial obligations upon step-parents. For policy makers in government, the uncertainty and inconsistency in this area of law reflects, in part, the pull of conflicting value judgments and policy choices about the nature and social role of step-families and indicates the need for further policy clarification" (lo destacado entre paréntesis y en cursiva es mío).

En los países del <<common law $>$ se ha denominado a estos padres como <<step-parents $>>$ y se les ha definido como el padre que convive con el padre custodio.

Otros casos se refieren a los derechos del padre que ha criado hijos ajenos, sin saberlo. En el Derecho alemán, el $\$ 1607$ del $B G B$ establece un derecho a indemnización a favor del padre que ha criado un hijo ajeno, creyéndolo propio, contra el padre biológico. A esta figura se le denomina $<<$ Kuckuckskind $>>$ en alusión al pájaro que cría polluelos ajenos. El $\mathbb{S} 1607.3^{\circ}$ del $B G B$ establece que esta indemnización comprende los alimentos que enteró el padre engañado. Así, el párrafo precedente establece que "[l]a acción de alimentos de un hijo en 
debe en parte a la íntima relación que existe entre los principios de interés superior del niño e igualdad de los padres. Dicha relación lleva a que los sistemas jurídicos durante los últimos diez o treinta ańos -dependiendo del ordenamiento jurídico que se analice- hayan optado por establecer equilibrios entre las facultades y derechos de los padres, tendientes a un mejor desarrollo de los hijos ${ }^{3}$. Esto se contrapone con la tendencia que se puede apreciar en nuestro Derecho en que se asignan por sentencia judicial los derechos de filiación de forma unilateral a uno de los padres; y en que se privilegia a la madre, aplicando la discutible regla de la preferencia materna.

En definitiva, el presente artículo se estructura en las siguientes cinco partes: (1) sistema chileno de asignación de facultades y derechos de filiación; (2) los ordenamientos jurídicos con un sistema de contrapeso de facultades y derechos, que en la práctica se asemeja mucho a un sistema de patria potestad, cuidado, responsabilidad o autoridad compartido; (3) modificación del eje del sistema de la infancia: compatibilización de los principios de igualdad de los padres e interés superior del niño; (4) valoración del sistema chileno de asignación de facultades y derechos de filiación en caso de separación de los padres a la luz del derecho comparado y (5) conclusiones finales.

\section{1) SisTEMA CHILENO DE ASIGNACIÓN DE FACULTADES Y DERECHOS DE FILIACIÓN}

Antes de abordar la asignación de facultades y derechos de filiación, en el Derecho comparado, se hará una breve referencia a la situación chilena, que se compone de dos partes. La primera trata, brevemente por cierto, la evolución del sistema chileno de asignación de las facultades y derechos de filiación, y la segunda aborda el actual sistema de asignación

contra de un progenitor se puede hacer valer, de acuerdo las condiciones del inciso $2^{\circ}$ frase 1 , no respecto del otro progenitor, sino por un pariente no obligado al pago de alimentos o el cónyuge del otro progenitor, cuando estos paguen alimentos, aplicándose mutatis mutandis lo establecido en el inciso $1^{\circ}$ (de este párrafo) cuando un tercero haya mantenido al niño como padre".

Ruz LÁrtiga, Gonzalo (2010), "el derecho de visitas en Francia: un derecho de la persona en familia en la búsqueda del justo equilibrio entre derecho parental, interés del niño y prerrogativas de terceros", en: Revista Chilena de Derecho de Familia, Ruz Lártiga, Gonzalo (Director Científico), Abeledo Perrot, LegalPublishing Chile, t. 3, pp. 139-162 y Rogerson, Carol (2001) "The Child Support Obligation of Step-parents", en: Can J. Fam. Law, p. 9 (ver en: http://papers.ssrn.com/sol3/papers.cfm?abstract $\mathrm{id}=1300391$ ).

3 En la referencia al Derecho comparado solo se aborda el Derecho desde una visión eurocéntrica, analizándose algunos Derechos latinos (Italia y España) y de países del common law (Reino Unido y Estados Unidos de América), haciendo breves referencia a algún u otro país. 
de facultades y derechos de filiación en caso que los padres vivan separados.

\section{1) EVOLUCIÓN DEL SISTEMA CHILENO DE ASIGNACIÓN DE LAS FA- CULTADES Y DERECHOS DE FILIACIÓN}

El sistema chileno de asignación de derecho de filiación, sobre todo en caso que los padres vivan separados, es bastante peculiar, desde sus inicios. El Derecho Civil chileno hace una distinción inédita en el Derecho comparado entre cuidado personal y patria potestad. En razón de ella, los aspectos personales de la infancia se regulaban por el cuidado personal y los aspectos patrimoniales por la patria potestad. Naturalmente, conforme a la tendencia de la época, el poder sobre los hijos se concentraba en el padre y recaía sobre la descendencia legítima. Así, la definición de patria potestad, tanto en el Proyecto Inédito (artículo 260), como en el Código Civil chileno (ex artículo 240), concebía esta figura como el poder del padre sobre los hijos legítimos ${ }^{4}$. Ello iba unido a una mayoría de edad que se alcanzaba a los veinticinco años, aspecto respecto del cual Bello innovó por cuanto, al tiempo de la Colonia y durante los primeros tiempos de la independencia, no existía la emancipación por edad ${ }^{5}$. Sin perjuicio de lo cual, no cabe la menor duda que se trataba de un sistema basado en el poder del padre sobre los hijos, a través de la autoridad parental, patria potestad y cuidado personal, y sobre su cónyuge a través de la denominada potestad marital ${ }^{6}$.

Por otra parte, el poder de los padres sobre los hijos, alcanzaba incluso aspectos físicos (heredados del Derecho romano). De este modo, el ex artículo 233 del CCCh establecía que "[e]l padre tendrá la facultad de corregir i castigar moderadamente a sus hijos, y cuando esto no alcanzare,

$4 \quad$ Así, la definición de Bello señalaba: "[l]a patria potestad es el conjunto de derechos que la ley da al padre legítimo sobre sus hijos no emancipados" y agregaba a renglón seguido que "[e]stos derechos no pertenecen a la madre". Y el inciso segundo señalaba que "[l]os hijos de cualquier edad, no emancipados, se llaman hijos de familia, y el padre con relación a ellos, padre de familia”.

Obras Completas de Andrés Bello (1981): T. XIV, vol. I, Código civil, Casa de Bello, Caracas, Venezuela, p. 187.

5 López, A., Montés, V. L. y Roca, E. (1997): Derecho de Familia, Tercera Edición, Valencia, Tirant lo Blanch, pp. 15 y ss.

6 La manifestación de esta potestad del marido sobre su mujer, se apreciaba en que la cónyuge tenía una serie de deberes con relación a su marido, como los deberes de obediencia (ex artículo 131 del $C C C h$ ) y de vivir con el marido y seguirle en su domicilio (ex artículo 133.1º del $C C C h)$; pero además la cónyuge, que se casaba en sociedad conyugal -que era el único régimen posible a la promulgación del Código-, era una incapaz relativa (ex artículo 135 y 136 del $C C C h$ ), a cambio de todo ello el marido estaba obligado a recibir a su mujer en su casa (ex artículo $133.3^{\circ}$ del CCCh). 
podrá imponerles la pena de detención hasta por un mes en un establecimiento correccional.

Bastará al efecto la demanda del padre, y el juez en virtud de ella expedirá la orden de arresto.

Pero si el hijo hubiere cumplido diez y seis años, no ordenará el juez el arresto, sino después de calificar los motivos, y podrá extenderlo hasta por seis meses a lo más.

El padre podrá a su arbitrio hacer cesar el arresto”.

Los hijos, que no estaban amparados por el matrimonio de sus padres, eran estigmatizados, y la generación que proviniese de dichas uniones era calificada como inmoral. De este modo, jurídicamente a dichos niños se les denominaba como hijos adulterinos, de dańado ayuntamiento, sacrílegos e incestuosos. No es del caso referirse a esta época, pero el siglo XX haría que nuestra sociedad mutara desde una sociedad agrícola, eminentemente patriarcal, a una sociedad burguesa, que habitaba en las ciudades y que se relacionaba comercialmente a través de formas de contratación masiva. La influencia de la era de la industrialización en la familia fue muy relevante y se plasmaría fundamentalmente en la incorporación de las mujeres al campo del trabajo. Así, durante el primer tercio del siglo XX, se modificarían sucesivamente las normas que regulan la autoridad parental, la patria potestad y el cuidado personal. Curiosamente el advenimiento de esta nueva sociedad llevaría al asentamiento en Chile de la familia nuclear y a un aumento exponencial de los hijos matrimoniales ${ }^{7}$.

Sin embargo, estas modificaciones estarían centradas en un Derecho eminentemente paternalista, que protegía a la mujer y los hijos en situaciones de riesgo. Así, en las sucesivas reformas no se aprecia una verdadera vocación igualitaria. En el ámbito social lo que primaba era la intervención del Estado, más que el reconocimiento de la autonomía familiar o el desarrollo de los derechos de sus integrantes ${ }^{8}$. Estas modificaciones legales se extenderían a la protección de los hijos no matrimoniales en dos eta-

7 La familia nuclear, de acuerdo a la historia de Chile, ha sido una excepción, salvo entre los años treinta y setenta. Así, según Valdés, la tasa de hijos nacidos fuera del matrimonio en los años sesenta llega al piso histórico de $16 \%$ de los hijos nacidos vivos.

VALDÉs S., Ximena (2009) "El lugar que habita el padre en Chile contemporáneo. Estudio de las representaciones sobre la paternidad en distintos grupos sociales", en: Polis, Revista de la Universidad Bolivariana, Vol. 8, № 23, p. 389.

8 Las palabras de AlESSANDRI, a este respecto, son clarificadoras: "[s]i este temperamento podía explicarse por razones históricas (se refiere a la regla de asignación primaria del Código Civil), era insostenible jurídica y prácticamente. No se v[e], en realidad, ninguna razón para negar a la madre legítima la patria potestad sobre los bienes de sus hijos no emancipados. Por el contrario, nadie puede estar más indicada que ella, en defecto del padre, para administrar esos bienes. Comprendiéndolo asi (...) el decreto-ley 328, primeramente, y ley 5521, de 19 de diciembre de 1934, en seguida, confirieron a la madre legitima, en defeco del padre, los derechos de patria potestad sobre los bienes de sus hijos no emancipados en las mismas condiciones que a aquél, a menos que 
pas: Primero se abrogaron las categorías de hijos adulterinos, de dañado ayuntamiento, sacrílegos e incestuosos ${ }^{9}$, para mucho después derogar las categorías de hijos legítimos, naturales e ilegítimos, y establecer como principio la igualdad de los hijos ${ }^{10}$. El Derecho Civil de la Familia, durante esta época, fue una especie de Derecho Público asistencial. Por ello, no es de extrañar que una de las discusiones más relevantes, de aquellos tiempos, era si el Derecho de Familia era en realidad Derecho Público o Privado. Eran los tiempos en que se discutían las posiciones de Antonio Cicu, que seńalaba que el Derecho de Familia era eminentemente Derecho Público. Esta es una etapa fundamental en la evolución del Derecho de la Infancia, que se erige como un Derecho autónomo de los Derechos Matrimoniales y Patrimoniales, que se denominaría como Derecho de Menores. Sin embargo, este Derecho siguió siendo un Derecho eminentemente protector de los hijos y que privilegió la figura de la madre sobre la del padre. Respecto de esta etapa fundamentalmente protectora de los hijos y de la madre, solo nos referiremos a los hijos. En esta época aún se considera que los padres tenían una suerte de poder sobre los hijos, aunque esta vez el poder se centraría en la madre. La forma en la cual se articula esta discriminación respecto del padre, vendría dada por la asignación de forma unilateral del cuidado personal, la autoridad parental y la patria potestad, en los casos de conflicto, a la madre. Esta etapa del Derecho civil, como un Derecho protector de la mujer y de los hijos, no ha sido abandonada del todo. Y ello es natural desde que aún estamos lejos de alcanzar la igualdad entre hombres y mujeres. Pero, este Derecho Civil

esté divorciada por adulterio o privada del cuidado personal del hijo por su mala conducta (artículo 240)". (lo destacado entre paréntesis y cursiva y solo en cursiva es mío).

Alessandri Rodríguez, Arturo (1948): "el Código civil chileno y sus reformas", en: $R D J$, t. XLV, No 3 y 4, pp. 37 a 67 y (2010), en: Doctrinas Esenciales. Derecho Civil. Instituciones Generales, Tavolari Oliveros, Raúl (Director), Editorial Jurídica de Chile, Puntolex y Thomson Reuters, pp. 99 y 100.

9 Así, las leyes No 5.521 de 1934 y No 10.271 de 1952 introdujeron importantes modificaciones al Código Civil, permitiendo que la madre también tuviese la patria potestad. La Ley No 18.802 , a su vez, aclaró de forma definitiva que la patria potestad procedía también respecto de la madre.

10 La última de las leyes de esta clase fue la Ley de Filiación $(L F)$ de 1998, que modificó la regla anterior, al dejar sin efecto la distinción entre los hijos legítimo e ilegítimos. La LF modificaría el artículo $243.1^{\circ}$ del $C C C h$, definiendo a la patria potestad como "el conjunto de derechos y deberes que corresponden al padre o a la madre sobre los bienes de sus hijos no emancipados" y estableciendo en el inciso $2^{\circ}$ que "[l]a patria potestad se ejercerá también sobre los derechos eventuales del hijo que está por nacer". De este modo, se puso fin a la discriminación de los hijos en consideración a su origen, prohibiéndose hacer diferencias entre hijos matrimoniales y no matrimoniales.

Un Proyecto de Ley, de iniciativa de un grupo de diputados, que se discute en la actualidad en el Congreso, inspirado en el principio de igualdad de los hijos, plantea extender la declaración de bien familiar a los hijos no matrimoniales.

Ver Boletín № 8456-18, en: http://www.senado.cl/appsenado/templates/tramitacion/index. php [revisado el día 7 de diciembre del 2012]. 
meramente protector, sería complementado y aun desplazado por un Derecho basado en el desarrollo y protección de los derechos fundamentales. La influencia de los Derechos Fundamentales, en el Derecho de la Infancia, no se ha dejado esperar y ha exigido un cambio terminológico profundo, por ello ya no hablamos de Derecho de Menores, sino de Derecho de la Infancia y de la Adolescencia. De este modo, ha surgido un nuevo Derecho basado en principios, totalmente diferentes a los del Derecho Patrimonial, como los siguientes: el interés superior del niño, la igualdad de los padres, la intervención mínima del Estado en la Familia, la corresponsabilidad de los padres, el ejercicio progresivo de los derechos del niño y del adolescente.

En resumen, nuestro Derecho de la Infancia ha evolucionado en varias etapas: la primera fue un Derecho eminentemente patriarcal; luego, se da lugar a una segunda etapa marcada por un Derecho que se podría denominar de Menores que desplazó el poder del padre a la madre, y finalmente, estamos imbuidos en una tercera etapa mucho más evolucionada, que podríamos llamar como Derecho de la Infancia. Esta etapa, como veremos, se configura con relación a los padres por los principios del interés superior de los hijos, e igualdad de los padres, como manifestación de aquel.

\section{2) SISTEMA DE ASIGNACIÓN CHILENO DE FACULTADES Y DERECHOS DE FILIACIÓN EN CASO QUE LOS PADRES VIVAN SEPARADOS}

La regla de asignación legal y supletoria del cuidado personal, patria potestad y autoridad parental, en los casos de separación de los padres, se rige por $<<$ la regla de la preferencia materna $>>$. A este respecto los incisos $1^{\circ}$ de los artículos 225 y 245 del CCCh disponen que, "[s]i los padres viven separados, a la madre toca el cuidado personal de los hijos", y "[s] i los padres viven separados, la patria potestad será ejercida por aquel que tenga a su cargo el cuidado personal del hijo, de conformidad al artículo 225". La categorización en Chile, de la autoridad parental, ha sido tradicionalmente exigua y se ha convertido en una figura accesoria al cuidado personal ${ }^{11}$. A su vez, la regla de asignación judicial es una mezcla entre el principio del interés superior del niño y la regla de la preferencia materna, conforme a la interpretación que nuestros tribunales han hecho del artículo 225.3 del $C C C h^{12}$. Ello se debe a que a partir de una jurisprudencia de la Corte

11 Ver: Historia de la Ley. Compilación de la Biblioteca del Congreso Nacional, Santiago, año 2000, Volumen II, página 2741.

12 El cuidado personal, conforme a la disposición precedente, le corresponderá al padre, "cuando el interés del hijo lo haga indispensable, sea por maltrato, descuido u otra causa calificada". En cambio, la patria potestad podrá trasladarse de la madre al padre por resolución fundada en interés del hijo (artículo $245.2^{\circ}$ del CCCh). 
Suprema, que se asienta desde el año 2010, la <<otra causa calificada $>>$, a que hace referencia la norma precedente, debe valorarse conforme al interés superior del niño, y no conforme a la aplicación de los artículos 226 del CCCh y 42 de la $L P M$, como lo venían haciendo las Cortes de Apelaciones ${ }^{13}$.

\section{3) ACUERDOS DE LOS PADRES EN TORNO AL CUIDADO PERSONAL COMPARTIDO Y A REPARTIR LAS FUNCIONES QUE SE DESPREN- DEN DE LA FILIACIÓN}

El artículo $225.2^{\circ}$ del $C C C h$ no se refiere a ninguna de estas posibilidades; pero ello no puede llevar, como han sostenido varios autores, a desechar dicha posibilidad ${ }^{14}$. El que los padres, de estar separados, puedan optar por el cuidado compartido es ampliamente aceptado y promovido en el Derecho comparado. Dada la importancia del principio del interés superior del niño, como principio rector de la infancia, los padres podrán celebrar ambas clases de acuerdo, pero sujetos naturalmente a la autorización judicial. Esta autorización judicial -que no exige el artículo $225.2^{\circ}$ del $C C C h-$ no solo se sustenta en la obscuridad de esta norma, sino en el interés superior del niño. Así, para resolver este vacío regulatoria se puede recurrir al artículo $27.2^{\circ}$, segunda parte, de la $L M C^{15}$, que regula el contenido del acuerdo completo y suficiente. Naturalmente, nuestro Derecho tampoco se refiere a la posibilidad de dividir las funciones propias de la patria potestad, del cuidado personal o de la autoridad parental entre los padres, como si se acordare que uno se encargue de lle-

13 Ellos corresponden a los autos Roles No 608-2010 y 4.372-2010. Sin perjuicio de lo anterior la jurisprudencia de los tribunales aun entienden al principio del interés superior del niño como un principio de protección de este y asignan el cuidado personal al padre en caso que la madre no ejerza adecuadamente su labor. A pesar de ello las sentencias de los tribunales iban encaminadas a aplicar el interés superior del niño como una forma privilegiada de desarrollo de la personalidad del niño.

14 La mayoría de la dogmática chilena sostiene que no cabe en esta materia hacer una interpretación literalista de la norma. Ello es evidente desde que sí los padres pueden distribuir funciones estando juntos -en cuyo caso la asignación jamás será aprobada judicialmente- con mayor razón podrían hacerlo de llegar a un acuerdo al respecto estando separados.

En contra de la posición literalista están autores como Acuña, Court, Gómez de la Torre, y Lathrop. En contra Rodríguez P.

Acuña S.M., Marcela (2011) Efectos jurídicos del divorcio, Abeledo Perrot, Thomson Reuters, Santiago de Chile, pp. 397 a 403; Court M, Eduardo (2010) Curso de Derecho de Familia, la Filiación por Naturaleza, Abeledo Perrot, LegalPublishing, Santiago de Chile, 2010, p. 75 y Rodríguez Pinto, María Sara, el Cuidado Personal de Niños y Adolescentes, Abeledo Perrot, LegalPublishing, Santiago de Chile, 2010, pp. 47, 48, 50, 67 a 70 y 110 a 112.

15 En este sentido cabe recordar que, conforme al artículo $27.2^{\circ}$, segunda parte, de la $L M C$, el convenio regulador de la separación judicial y del divorcio "(...) [s]e entenderá que es suficiente si resguarda el interés superior de los hijos...". Es verdad que esta regla se refiere a los hijos matrimoniales, pero no existe motivo para no extenderla a los hijos no matrimoniales, aplicando el principio de no discriminación por razones de origen. 
var a los niños al colegio y los deberes escolares y el otro de las actividades extraprogramáticas o de la educación religiosa ${ }^{16}$.

\section{2) ORDENAMIENTOS JURÍdicos CON UN SISTEMA DE CONTRAPESO DE FACULTADES Y DERECHOS QUE EN LA PRÁCTICA SE ASEMEJA MU- CHO A UN SISTEMA DE PATRIA POTESTAD, CUIDADO, RESPONSABI- LIDAD O AUTORIDAD COMPARTIDO}

En estos Derechos la guarda y custodia compartida es una manifestación de la responsabilidad parental ${ }^{17}$, que permite que ambos progenitores por acuerdo, ley o decisión judicial mantengan una relación viable entre ellos, basada en el respeto y en la colaboración, con el objeto de facilitar la más frecuente y equitativa relación filial, tanto en el aspecto cotidiano como en torno a los derechos y facultades propios de la filiación ${ }^{18}$.

A continuación se analizará la evolución de varios de los ordenamientos jurídicos, que han dejado de lado la asignación de derechos de facultades y derechos de filiación exclusivos o unilaterales -aunque esta asignación se sustente en el principio del interés superior del niño-, para en definitiva establecer un sistema de derechos y facultades equilibrados entre los padres que se sustenta en el interés del hijo. El abandono del sistema anterior ha sido inevitable desde que el Derecho de Infancia ha evolucionado desde un sistema que distingue entre titularidad y ejercicio de facultades y derechos de filiación, a uno que se centra solo en el ejercicio de dichas facultades y derechos. Por ello, un grupo importante de ordenamientos jurídicos ya no se articula a través de la figura del padre no custodio, sino en establecer facultades y derechos comunes a los padres, que excepcionalmente pueden ser indistintos, conforme al principio del interés superior del niño ${ }^{19}$. En cierto modo este ha sido el devenir natural de los ordenamientos jurídicos que asignaban facultades y derechos de filiación de forma exclusiva y se preocupaban del padre no custodio,

16 Court M. señala que se ha entendido que los padres pueden alternarse el cuidado personal conforme a la edad del niño, acordando un cuidado alternativo, o compartido.

Court Murasso, Eduardo (2010): Curso de Derecho de Familia, la Filiación por Naturaleza, Abeledo Perrot, LegalPublishing, Santiago de Chile, p. 75.

17 El Reglamento 2201/2003 de la UE (CE) No 2.201/2.003 del Consejo de Europa, de 27 de noviembre de 2003, en su artículo $2.7^{\circ}$ define la responsabilidad parental como: "[l] os derechos y obligaciones conferidos a una persona física o jurídica en virtud de una resolución judicial, por ministerio de la ley o por un acuerdo con efectos jurídicos, en relación con la persona o los bienes de un menor. El términos incluye, en particular, los derechos de custodia y visita”.

18 Este concepto, salvo la primera parte y la final se desprende de lo señalado por Ortuño.

Ortuño Muñoz, Pascual (2005): Tratado de derecho de Familia, aspectos sustantivos y procesales, Madrid.

19 Una de las variantes de este sistema de asignación unilateral distinguía entre titularidad y ejercicio, como hacia fuertemente el Derecho español antes de la reforma del 2005. 
aplicando los principios del interés superior del niño y de igualdad de los padres. Este sistema lo que pretendía es que la separación de los padres no se traspasase a los hijos y que ellos obtuviesen lo mejor de ambos padres. Lo anterior supone que el ordenamiento jurídico es capaz de establecer un equilibrio, que permite que los padres puedan negociar y llegar a acuerdos cooperativos, que se hagan cargo de los distintos aspectos de relevancia para la formación de sus hijos.

\section{1) ITALia DESPUÉS DE LA REFORMA DEL 2006}

La doctrina italiana hace tiempo que venía reconociendo esta situación como un derecho del hijo a ambos padres, es decir, a la $<<$ bigenitorialità $>>^{20}$. El actual sistema italiano de asignación de derechos y facultades de filiación se sustenta en el artículo 155 del Codice Civile ${ }^{21}$, modificado por la Reforma del $2006^{22}$.

20 Finocchiaro, M. (2006). "Riconosciuto anche alla prole il diritto di frequentare i genitori", en: Guida al dir., pp. 11 y ss.

21 La reforma del 2006, introducida por la Ley $\mathrm{N}^{\circ} 54$, de 8 de febrero, modificó la redacción del artículo 155 del Codice Civil, y agregó los artículos 155 bis, ter, quarter, quinquies y sexies.

El nuevo artículo 155 del Codice Civil es del siguiente tenor:

«Art. 155 (Medidas relativas a los hijos) Además, en caso de separación de los padres, el hijo menor tiene derecho a mantener una relación directa y regular con cada uno de ellos, para recibir el cuidado, la educación y la instrucción de ambos y sostener vínculos significativos con los ascendientes y parientes de cada progenitor.

Para alcanzar los fines establecidos en el inciso primero, el juez que dictamina la separación de los cónyuges deberá adoptar las medidas relativas a la descendencia con exclusiva observancia al interés moral y material de la misma. Ponderará preeminentemente que los hijos menores sean custodiados por ambos padres o bien, determinará a cuál de ellos se le asignará el cuidado personal de los hijos, fijando la periodicidad y el modo en que se configura la presencia de cada uno de los padres, además establecerá el alcance y modo en que cada uno de ellos debe contribuir a la manutención, cuidado personal, instrucción y educación de los hijos. Se levantará acta de los acuerdos logrados entre padres, siempre que no sea contrario al interés superior de los hijos. Resolverá cualquier otra medida relativa a la prole.

La patria potestad será ejercida por ambos padres. Las decisiones de mayor relevancia para los hijos relativas a su instrucción, educación y salud se tomarán de común acuerdo, teniendo en cuenta la capacidad, la inclinación natural y las pretensiones de los hijos. En caso de desacuerdo, la decisión quedará en poder del juez. En cuanto a las decisiones que se limitan a la administración ordinaria, el tribunal podrá determinar que los padres ejerzan la patria potestad por separado.

Salvo acuerdo en contrario libremente suscrito por las partes, cada padre proveerá a la manutención de los hijos en proporción a sus ingresos, el tribunal establecerá, cuando sea necesario, la correspondiente pensión periódica conforme al principio de proporcionalidad, que se determinará teniendo en cuenta:

1) Las necesidades actuales del hijo;

2) El nivel de vida disfrutado por el hijo en coherencia a la convivencia con ambos padres;

3) El tiempo de permanencia con cada padre;

4) Los recursos económicos de los padres;

5) La valoración económica de las tareas domésticas y el cuidado asumido por cada padre.

La pensión se adaptará automáticamente conforme al índice ISTAT, en ausencia de otro parámetro proporcionado por las partes o por el tribunal.

Cuando la información económica proporcionada por los padres no sea suficientemente documentada, el juez corroborará la información a través de la policía tributaria respecto los ingresos 


\section{$\operatorname{tos}^{23}$ : \\ El sistema italiano se estructuraría sobre los siguientes dos cimien-}

a) El Derecho debe velar por la mantención del vínculo de filiación y por el ejercicio por parte de ambos padres de las facultades y derechos de filiación; incluso en el caso de separación de los padres (artículo 155.1 del Codice Civile). Los hijos tienen derecho a mantener una equilibrada y continua relación con cada uno de los padres para recibir la atención

y los bienes objeto de la contestación de la demanda, determinando también si fueron atribuidos a personas diversas".

El actual artículo 155 del Codice Civil italiano obedeció al deseo de diseñar un sistema acorde con el propuesto por la Convención de Naciones Unidas sobre Derechos del Niño (ver artículos $3,2,5,9,10.2^{\circ}$ y $14.2^{\circ}$ de la Convención). Así, se promulgó un sistema que establece un adecuado balance entre las facultades y deberes de los padres, respetando los principios de igualdad de los padres e interés superior del niño. Esta regulación se condice muy bien con el artículo $14.2^{\circ}$ de la Convención de Derechos del Niño, que establece que "[l]os Estados Partes respetarán los derechos y deberes de los padres y, en su caso, de los representantes legales, de guiar al niño en el ejercicio de su derecho de modo conforme a la evolución de sus facultades". A este respecto no está mal recordar que dicha Convención, por su data, solo establece un catálogo de $<<$ mínimos >> en cuanto al desarrollo de los Derechos Fundamentales de la infancia y la adolescencia.

Por otra parte, la nueva normativa, agregada al Codice, establece la posibilidad de decretar la custodia compartida con oposición de un padre (artículo 155 bis); el que el juez pueda revisar en cualquier momento las decisiones adoptadas con relación a los hijos (artículo 155 ter); la adopción por parte del juez de medidas relacionadas con la declaración del bien familiar o <<assegnazione della casa familiare e prescrizioni in tema di residenza>> (artículo 155 quáter); la regulación de pensiones en favor de los hijos adultos que no sean independientes (artículo 155 quinquies); y establece facultades en torno al deber del juez de oír al nińo y de ayudar a la celebración de acuerdos por parte de los padres (artículo 155 sexies).

Ver: http://www.camera.it/parlam/leggi/06054l.htm, consultado el 29 de mayo del 2012.

DeL VAS describe de forma muy acertada a la modificación italiana del 2006, cuando señala que "[e]n esta dirección, la Ley 54/2006, en línea con los principios consagrados por la Convención sobre los Derechos del Niño de 1989, tiene como objetivo prioritario favorecer las relaciones equilibradas con ambos progenitores, también en el caso de disolución de la familia, para ofrecer una tutela continuada y uniforme a los hijos, al margen, por tanto, de la naturaleza de la unión entre los progenitores y de sus posibles avatares. Se trata de una perspectiva de particular importancia, toda vez que, como dispone el artículo 4.2 de la mencionada Ley, sus disposiciones se aplican incluso en los supuestos de divorcio, de cesación de los efectos civiles y nulidad del matrimonio o de procedimientos relativos a los hijos de progenitores no casados entre sí. Esta previsión viene a colmar una laguna del sistema, que no contenía ninguna norma para la regulación de la disolución de la pareja de padres no casados en relación con la custodia de sus hijos".

Del Vas González, Juan María (2010): "Rottura della famiglia e interesse dei figli en el Derecho Civil italiano" en: Revista Crítica de Derecho Inmobiliario, núm. 717, p. 212.

23 La importancia de la modificación introducida el 2006, a la regulación italiana, se puede apreciar en las siguientes palabras de DeL VAS "[e]stablece a continuación el precepto (se refiere al artículo 155 del Codice) que las decisiones de mayor interés para los hijos, relativas a su instrucción, educación y salud, serán adoptadas por ambos de común acuerdo, teniendo en cuenta la capacidad, las inclinaciones naturales y las aspiraciones de los hijos (nota al pie). En caso de desacuerdo, la decisión corresponderá al Juez. A diferencia de la prescripción contenida en el artículo 316.3 del Código Civil (nota al pie), se percibe aquí que es el Juez quien adopta la decisión, sin atribuirla a aquel de los progenitores que él estime más idóneo para la protección de los intereses del menor (nota al pie)" (lo destacada entre paréntesis y cursiva es mío).

Del Vas (2010) 216. 
médica, la educación y la instrucción de ambos y mantener relaciones significativas con ancestros y familiares de cada rama de la familia de sus padres. Es más, de acuerdo a la norma precedente, para alcanzar dichos fines, el juez, que dé lugar a la separación de los cónyuges, adoptará las medidas relativas a la descendencia, guiado exclusivamente por los intereses morales y materiales de la descendencia.

b) El juez puede dar lugar al cuidado o custodia exclusiva a favor de uno de los padres, pero debe preferir la custodia conjunta. En los casos en que el juez otorgue el cuidado de forma exclusiva debe velar y determinar qué funciones se ejercen de forma conjunta. La jurisprudencia italiana, determinando el alcance del artículo $155.2^{\circ}$ del Codice Civile, ha resuelto que la custodia compartida no tiene que ver necesariamente con el establecimiento, sino con que las facultades y derechos de la filiación sean conjuntos como la educación o el esparcimiento ${ }^{24}$.

\section{2) ESPAÑA DESPUÉS DE LA REFORMA DEL 2005}

El Derecho español no ha recibido modificaciones sustanciales a las reglas de asignación de las facultades y derechos de filiación en materia de asignación legal supletoria o mediante resolución judicial ${ }^{25}$. Sin perjuicio de lo cual, el sistema jurídico español ha transitado hacia un sistema de

24 En este sentido DEL VAS nos aclara que "[p]ara ir perfilando los contornos de esta nueva figura (se refiere a la custodia compartida establecida en el inciso $2^{\circ}$ del artículo 155), podemos decir que la expresión "custodia compartida», empleada por el legislador en el título de la Ley y del artículo 155 bis, sin haber precisado siquiera sus caracteres, evoca una idea de coparticipación de los progenitores en las funciones de cuidado y crecimiento del hijo. Compartir significa literalmente partir con alguien y, en el caso que nos ocupa, cada progenitor parte con el otro el cuidado y funciones educativas de los hijos. En este sentido ha precisado la jurisprudencia que la característica peculiar de esta nueva tipología de custodia reside, no ya en la dualidad de la residencia o en la paridad del tiempo de permanencia del hijo con uno y otro progenitor, sino en la condivisión paritaria de su función como padres" (lo destacado entre paréntesis y cursiva es mío).

DeL VAS (2010) 215.

25 La Reforma espańola, del 2005, establece el cuidado compartido, pero de forma restrictiva por cuanto excepcionalmente este puede imponerse por el juez con oposición de uno de los padres. De este modo, tanto el juez como las partes, a través del convenio regulador, pueden imponer o convenir la guarda compartida (artículo $95.5^{\circ}$ y $8^{\circ}$ del CCE).

A pesar que los tribunales ya venían, hace algún tiempo, aceptando la guarda compartida, la Ley No 15/2005 introdujo de forma definitiva esta figura al Derecho español. Sin embargo, la regla general, en el Derecho español, sigue siendo la asignación de la custodia exclusiva a uno de los padres. Lo anterior no obsta a que los padres pidan al juez la custodia compartida o así lo acordaren, como se desprende del no 5 del artículo 92 el CCE. Incluso, excepcional y calificadamente el juez puede decretar la custodia compartida, a pesar de la oposición de uno de los padres, en la medida que se cumplan las condiciones establecidas en el $n^{\circ} 8$ del artículo 92 del $C C E$.

En este sentido, el nuevo artículo 92 del CCE establece que “...5\% Se acordará el ejercicio compartido de la guarda y custodia de los hijos cuando así lo soliciten los padres en la propuesta de convenio regulador o cuando ambos lleguen a este acuerdo en el transcurso del procedimiento. El Juez, al acordar la guarda conjunta y tras fundamentar su resolución, adoptará las cautelas 
facultades y derechos de filiación conjuntos. La regla de asignación legal supletoria, en los casos en que los progenitores estén separados, es que el ejercicio de la patria potestad corresponderá al padre que conviva con el menor; pero el otro padre puede recurrir al juez, de acuerdo al artículo $156.5^{\circ}$ del CCE, para que en interés del hijo, atribuya "al solicitante la patria potestad para que la ejerza conjuntamente con el otro progenitor o distribuir entre el padre y la madre las funciones inherentes a su ejercicio". En cambio, en torno al cuidado personal, conforme al artículo 159 del CCE, "[s]i los padres viven separados y no decidieren de común acuerdo, el juez decidirá, siempre en beneficio de los hijos, al cuidado de qué progenitor quedarán los hijos menores de edad. El juez oirá, antes de tomar esta medida, a los hijos que tuvieran suficiente juicio y, en todo caso, a los que fueran mayores de doce años". La titularidad de la patria potestad continuará siendo conjunta, conforme al artículo $154.1^{\circ}$ y $2^{\circ}$ del CCE.

procedentes para el eficaz cumplimiento el régimen de guarda establecido, procurando no separar a los hermanos.

$6^{\circ}$ En todo caso, antes de acordar el régimen de guarda y custodia, el Juez deberá recabar informe del Ministerio Fiscal, y oír a los menores que tengan suficiente juicio cuando se estime necesario de oficio o a petición del Fiscal, partes o miembros del Equipo Técnico Judicial, o del propio menor, valorar las alegaciones de las partes vertidas en la comparecencia y la prueba practicada en ella, y la relación que los padres mantengan entre sí y con sus hijos para determinar su idoneidad con el régimen de guarda.

$7^{\circ}$ No procederá la guarda conjunta cuando cualquiera de los padres esté incurso en un proceso penal iniciado por atentar contra la vida, la integridad física, la libertad, la integridad moral o la libertad e indemnidad sexual del otro cónyuge o de los hijos que convivan con ambos. Tampoco procederá cuando el Juez advierta, de las alegaciones de las partes y las pruebas practicadas, la existencia de indicios fundados de violencia doméstica.

$8^{\circ}$ Excepcionalmente, aun cuando no se den los supuestos del apartado cinco de este artículo, el Juez, a instancia de una de las partes, con informe favorable del Ministerio Fiscal, podrá acordar la guarda y custodia compartida fundamentándola en que solo de esta forma se protege adecuadamente el interés superior del menor.

$9^{\circ}$ El Juez, antes de adoptar alguna de las decisiones a que se refieren los apartados anteriores, de oficio o a instancia de parte, podrá recabar dictamen de especialistas debidamente cualificados, relativo a la idoneidad del modo de ejercicio de la patria potestad y del régimen de custodia de los menores".

Sin perjuicio de lo anterior, como destaca Guilarte, las sentencias del TS, de 8 de octubre de 2009, 10 de marzo de 2010 y 11 de marzo de 2010, han resuelto que el apartado $8^{\circ}$ de la norma precedente es excepcional y se concede en el caso que lo único conveniente para el hijo sea la custodia compartida, lo que hace que este régimen no solo sea excepcional, sino de difícil ocurrencia.

Guilarte Martín-Calero, Cristina (2010): "Criterios de atribución de la custodia compartida. A propósito de la línea jurisprudencial iniciada con la Sentencia del Tribunal Supremo de 8 de octubre de 2009" en: InDret, Revista de Análisis del Derecho, Julio, Barcelona, España, (http://www.indret.com/pdf/753_es.pdf, consultado el 14 de mayo del 2012).

Sin perjuicio de lo anterior, no se puede dejar de lado que el Derecho español cuenta con una serie de Comunidades Autónomas con Derechos forales históricos, que se han plasmado en una particularmente rica regulación de Derecho de familia que por su extensión el presente trabajo no considerará. 
En definitiva, en el Derecho español la regulación del Código Civil permite que, vía jurisprudencial, se establezca una distribución conjunta o indistinta de las facultades y derechos que derivan de la filiación, específicamente con relación al ejercicio de la patria potestad. Es más, la mayoría de la doctrina señala que el ejercicio sigue siendo conjunto a pesar de la separación de los padres. Sin embargo, tras la Reforma del 2005, tanto la doctrina como la jurisprudencia han optado a favor del cuidado o guarda exclusivo. Ello es natural en un país en que la titularidad y el ejercicio de la patria potestad es conjunto. En este sentido, el desarrollo jurisprudencial se ha dado por lo que se entiende por facultades - deberes indistintos respecto del padre no custodio, como los siguientes: auxilio, cooperación y vigilancia, manteniéndose el ejercicio conjunto en torno a los deberes facultades de velar por los menores; tenerlos en su compañía; educarlos, etc. ${ }^{26}$. Este sistema se diferencia del italiano por cuanto establece un cui-

26 Esta evolución del Derecho español se puede apreciar de lo declarado en el III Encuentro Institucional de Jueces y Magistrados de familia, Fiscales y Secretarios Judiciales, con Abogados de la Asociación Española de Abogados de Familia, celebrado en Madrid los días 28, 29 y 30 de octubre de 2008. A este respecto cabe destacar las siguientes conclusiones:

" 1 ․ Se concluye que el término custodia hace referencia a convivencia, no implicando más derechos, y consecuentemente no supone un status privilegiado de un progenitor frente al otro. Se valora positivamente la reforma llevada a cabo por la Ley No $15 / 05$, en el sentido de que en las resoluciones judiciales se han fijado unas estancias más equitativas con los hijos, ampliándose el tiempo de convivencia, que se había estandarizado, con el progenitor no custodio.

$2^{\circ}$. Explicar en las resoluciones judiciales el contenido de la Patria Potestad, que podría ser el siguiente:

$<<$ Ambos progenitores mantendrán el ejercicio conjunto de la patria potestad, de acuerdo con lo dispuesto en los arts. 154 y 156 del CC. Por tanto deberán comunicarse todas las decisiones que con respecto a su hijo adopten en el futuro, así como todo aquello que conforme al interés prioritario del hijo deban conocer ambos padres. Deberán establecer el cauce de comunicación que mejor se adapte a sus circunstancias obligándose a respetarlo y cumplirlo. Si no lo señalan la comunicación se hará... debe concretarse el que mejor se acomode al caso concreto y el otro progenitor deberá contestar... Si no contesta podrá entenderse que presta su conformidad. Ambos padres participaran en las decisiones que con respeto al hijo tomen en el futuro siendo de especial relevancia las que vayan a adoptar en relación a la residencia del menor o las que afecten al ámbito escolar, o al sanitario y los relacionados con celebraciones religiosas. Sobre esa base se impone la decisión conjunta para cualquier tipo de intervención quirúrgica o de tratamiento médico no banal tanto si entrańa un gasto como si está cubierto por algún seguro. Se impone igualmente la intervención y decisión de ambos padres en las celebraciones religiosas, tanto en lo relativo a la realización del acto religioso como al modo de llevarlo a cabo sin que al respecto tenga prioridad el progenitor a quien corresponda el fin de semana correspondiente al día en que vaya a tener lugar los gastos.

Los dos padres deberán ser informados por terceros de todos aquellos aspectos que afecten a su hijo y concretamente tienen derecho a que se les facilite a los dos toda la información académica y los boletines de evaluación e igualmente tienen derecho a obtener información a través de las reuniones habituales con los tutores o servicios de orientación del centro escolar tanto si acuden los dos como si lo hacen por separado. De igual manera tienen derecho a obtener información médica de sus hijos y a que se les faciliten los informes que cualquiera de los dos soliciten.

El progenitor que en ese momento se encuentre en compañía del hijo podrá adoptar decisiones respecto al mismo sin previa consulta en los casos en los que exista una situación de urgencia o 
dado personal indistinto como regla general; pero se asemeja en que en definitiva la distinción entre titularidad y ejercicio de la patria potestad permite sortear los escollos que crea un sistema de asignación exclusiva del cuidado personal. Sin perjuicio de lo anterior, existen importantes fallos del TS que han acelerado el proceso de establecimiento del cuidado personal compartido como la regla general ${ }^{27}$. Así, las sentencias precedentes han interpretado el artículo $92.8^{\circ}$ del $C C E^{28}$, resolviendo que el cuidado personal compartido con oposición de uno de los padres es una medida de excepción, solo en atención a que los padres acuerden el cuidado personal compartido $^{29}$. Otro tanto ocurre respecto del sistema alemán, sobre todo después del fallo del TC alemán, de 21 de julio del 2010, que se analiza más adelante, y de la consiguiente reforma que generó.

\section{3) El REINO UNIDO DESPUÉS DE LA $<<$ CHILDREN ACT >> DE 1989}

En el Reino Unido, la Reforma de 1989, establecería la $<<$ parental responsibility>> como criterio general para la asignación y ejercicio de derechos y facultades de los padres en la separación ${ }^{30}$. La referida Ley de 1989 cubre el conjunto de obligaciones, facultades y autoridad de los pa-

en aquellas decisiones diarias, poco trascendentes o rutinarias que en el normal transcurrir de la vida con un menor puedan producirse $>>$ ".

ZarraluQui Navarro, Elena (2010): Guarda y custodia vs patria potestad en cuanto a las residencia de los hijos menores, Derecho de Familia, Novedades en dos perspectivas, Asociación Española de Abogados de Familia, Dykinson, Madrid, España, pp. 163 y 164.

$27 \quad$ Ver sentencias del TS de 7 de julio del 2011 y 22 de julio del 2011.

28 El artículo $92.8^{\circ}$ del $C C E$ dispone "[e]xcepcionalmente, aun cuando no se den los supuestos del apartado cinco de este artículo (se refiere a la posibilidad que ambos padres pidan al juez que decrete el cuidado compartido o de establecerlo por acuerdo), el Juez, a instancia de una de las partes, con informe del Ministerio Fiscal, podrá acordar la guarda y custodia compartida fundamentándola en que solo de esta forma se protege adecuadamente el interés superior del menor (lo señalado entre paréntesis y cursiva es mío)".

29 El fallo del TS, de 22 de junio de 2011 (RJ 2011, 5676), como destaca PÉREZ, es especialmente relevante cuando resuelve que "[1] a excepcionalidad a que se refiere el inciso del párrafo 8, debe interpretarse, pues, en relación con el párrafo cinco del propio artículo que admite que se acuerde la guarda y custodia compartida cuando así lo soliciten ambos progenitores o uno con el acuerdo del otro. Si no hay acuerdo, el Art. 92.8 CC no excluye esta posibilidad, pero en este caso, debe el Juez acordarla fundamentándola en que solo de esta forma se protege adecuadamente el interés superior del menor".

Pérez Conesa, Carmen, "Excepcionalidad de la salomónica medida sobre custodia compartida en el Código Civil. Algunas referencias jurisprudenciales y legales”, en: la Semana Jurídica, semana 15 al 19 de abril de 2013, Año I, N 43, Thomson Reutres, p. 8.

30 Como destaca Probert, las razones del cambio terminológico, citando a Lord Chancellor (MaCKay (1989): 139 New L.J. 505), son profundas y radican en que "the reason and sole justification for parental status $>>$ is <<the duty to raise the child to become a properly developed adult both physically and morally $>>$ ".

De este modo, el cambio terminológico busca es cambiar el foco de atención del Derecho de la Infancia desde los derechos de los padres a los derechos del niño, como proceso en desarrollo.

Probert, Rebecca (2009): Cretney and Probert's Family Law, School of Law, University of Warwick, Sweet \& Maxwell, England and Wales, p. 242. 
dres sobre los hijos, pero cambiando la terminología de derechos y obligaciones por responsabilidad parental. Uno de los aspectos que nos interesa de esta ley es que la $<<$ parental responsibility $>>$ puede ser compartida por los padres e incluso puede compartirse con terceros. Dichos terceros pueden ser individuos, mediante la $<<$ child's guardian $>>$, o autoridades locales que operan a través de una $<<$ careorder $>>$ o una $<<$ emergency protection order $>>$. Sin embargo, esta intervención en la familia se produce solo en casos graves. Como destaca BaLdijeva, estas facultades de los terceros no impiden el ejercicio de la $<<$ parental responsibility $>>$ por parte de los padres, todo lo cual se sustenta en el interés y los derechos del niño ${ }^{31}$. Ello ha llevado a distinguir, como destaca Probert, entre intervenciones de los tribunales, basadas en problemas de Derecho Privado $(<<$ private law $>>)$ y de Derecho Público $(<<\text { public law }>>)^{32}$. Esta diferencia se desprendería del art. 8 de la Ley de la Infancia de 1989 y ha dado lugar a una nutrida jurisprudencia. Esta regulación es interesante por cuanto las decisiones relevantes se toman de común acuerdo por los padres, y en caso que no haya acuerdo uno de ellos puede recurrir a la Corte $(<<p r i-$ vate law>>); pero también es posible que se recurra contra la decisión de los padres, básicamente buscando la protección de los niños, por alguna autoridad local (<<public law >>) 33 .

En cuanto al tema que nos convoca, bajo la Ley de 1989, se debe distinguir entre $<<$ legal parenthood $>>$ y $<<$ parental responsibility $>>$. La primera solo dice relación con el deber de manutención respecto de los hijos, en cambio la segunda expresión tiene los alcances que se han indicado precedentemente. En la asignación de estos derechos cabe hacer las siguientes distinciones. En caso que los padres estén casados la $<<$ parental responsibility>> es conjunta (section 2 (1) de la Ley de 1989); en caso que los padres no lo estén, a la madre le corresponde la $<<$ parental responsibility > (section2 (2) de la Ley de 1989). Pero al padre, que no está casado con ella, no se le discrimina, por cuanto el adquiere la $<<$ parental responsibility > a través de tres mecanismos. Los dos primeros están en la Ley de 1989 y el tercero en la Ley de Adopción del 2002 (Adoption and Children $A c t)$. El proceso de reconocimiento no es automático, solo se puede otorgar conjuntamente con la madre, mediante acuerdo, <<statutory declaration $>>$ o orden de la Corte ${ }^{34}$. Los procedimientos de reconocimientos son los siguientes:

31 BaLdijeva, Miglena (2003): The concept of parental responsibility in Bulgarian and English Law, en Perspectives for the unification and harmonization of Family Law un Europe, Intersentia, pp. 403 a 404.

32 Probert (2009) 242.

33 Probert (2009) 220 y 221.

34 La forma de registro conjunto <<joint birth registration $>>$, es la general respecto de los padres no casados y solo cae a un $27 \%$ respecto de los padres que no tienen una relación de convivencia. 
a) El reconocimiento del hijo conjuntamente con la madre (art. 4 de la Ley de 1989, modificado por el art. 111 de la Ley de Adopción del 2002).

b) Un acuerdo de responsabilidad parental (<<parental responsibility agreement $>$ ).

En estos acuerdos de reconocimiento, que se rigen por la Section 4 (1) (b) de la Ley de Adopción, participa un funcionario de la Corte como testigo y posteriormente debe registrarse en $<<$ Principal Registry of the Family Division $>>{ }^{35}$.

c) Una orden de la Corte ( $<<$ parental responsibility order $>>)$.

Este supuesto está regulado en el artículo 4 (1) (a) de la Ley de 1989. La demanda deber ser presentada por el padre y es evaluada por la Corte, conforme al nivel de compromiso que este ha demostrado con relación al hijo y lo razonable que es la petición. Pero lo esencial es $<<$ the welfare principle>>, como se resolvió en los casos $\operatorname{Re} H, \operatorname{Re} M$ y $R e H$.

El sistema del Reino Unido es sumamente interesante por cuanto en el fondo lo que evalúa es la cercanía del padre con relación al hijo. Pero, además, ello se puede demostrar mediante el reconocimiento conjunto con la madre, el acuerdo de reconocimiento o el juicio de reconocimiento. El padre por ende que reconoce tiene necesariamente $<<$ parental responsibility $>>$. Ello es natural a la filiación y solo se le desconocen estos derechos al padre mediante una orden de la Corte, que se base en el interés superior del niño.

Para aclarar esta situación se puede consultar el caso Re $M$ (Contact: Family Assistance: McKenzie Friend) [1999] 1 F.L.R. 75, CA. En dicha causa a un padre se le concede la $<<$ parental responsibility $>>$, resolviendo la Corte que la concesión es alarmantemente obvia (<<startlingly obvious $>>$ ) por cuanto el padre se había preocupado de comunicarse con su hijo y había cumplido con su deber de alimentos (preocupándose de los gastos por $£ 400$ mensuales). Además, los temores de la madre, en torno al abuso de los derechos que podría hacer el padre, corresponden a una materia que se rige por otro procedimiento dentro de la ley ${ }^{36}$. Estos casos

35 Como destaca Probert la presencia del funcionario, que pudiere parecernos extraña se fundamente en la protección de la madre. Así, lo que se busca evitar la norma precedente es ejercer una coerción indebida sobre aquella.

Probert (2009) 250.

36 El texto de la Corte, destacado por Probert, es el siguiente: "In Re M (Contact: Family Assistance: McKenzie Friend) [1999] 1 F.L.R. 75, CA, the father had displayed considerable commitment to the children, and they to him; and he was paying $£ 400$ monthly for their support. The mother had a genuine fear of the father and opposed the application. But the Court of Appeal held that it was $<<$ startlingly obvious $>>$ that the order should have been made. The $<<$ fundamental aspect of the parental responsibility order ... is that it is a matter of status $>>$ (per Ward L.J.). It was $<<$ essential for the well-being of the children, especially where they are denied face to face contact, to begin to know that their father was concerned enough to make an application to be recognized as their father, and that his status as their father has the stamp of the 
son valorados por la Corte en concreto y de acuerdo al $<<$ the welfare principle $>>$. Naturalmente, la Corte debe actuar en caso de un tratamiento inadecuado o cruel (<<misuse $>>)$ por parte del padre.

\section{4) Los Estados UNIDOS DE AMÉRICA Y LA CUSTODIA COMPARTIDA}

En los Estados Unidos de América, la regla de la <<tender years presupmption >> ha sido totalmente dejada de lado. Así, en la Ley del Estado de Arkansas la custodia debe concederse, sin atener ni a la edad ni al sexo de los padres, y la Corte solo debe considerar el $<<$ the welfare and best interest of the children $>>$. Incluso en un caso curioso, Warner $v$. Warner, la Corte de Indiana otorgó la custodia de un niño pequeño al padre que acreditaba poseer importantes habilidades respecto de la alimentación del hijo ${ }^{37}$. En estos procesos, la opinión del niño debe obtenerse directamente por los tribunales, que deben seguir protocolos preestablecidos. La edad es un factor importante, que concurre con otros como el sustento del niño, su opinión, la hostilidad de uno de los padres hacia el otro padre, la preferencia por los hermanos, y la influencia y relación de uno de los padres con relación al otro ${ }^{38}$.

Sin perjuicio de lo anterior, los Estados Unidos de América se han comenzado a inclinar por la custodia compartida como régimen legal supletorio $^{39}$; pero la Corte siempre mantiene la facultad de asignar el cuidado a uno de los padres en caso que la custodia compartida cause detrimento al hijo (<<detrimental to the child $>>)$, como sucede en Florida (Fla. Stat. Ann S 61.13.2), o simplemente cuando ello sea mejor para el hijo conforme al <<best interests of the child $>>$, como sucede en Lousiana (art. 131 La. Civ. Code Ann $)^{40}$, Oregon, Iowa y Maine. Es más, como destaca Meyer, en algunos Estados - como en North Dakota - se ha establecido como regla general el cuidado conjunto, salvo inhabilidad de uno de los padres $(<<\text { unfit }>>)^{41}$. Sin perjuicio de lo cual, los alcances de la custodia compartida (<<joint custody $>>)$ no han estado exentos de críticas

court's approval >>. The court noted that other procedures were available under the Children Act if the father abused his rights".

Probert (2009) 251.

De Witt Gregory, John, N. Swisher, Peter y L. Wolf (2005). Sheryl Understanding Family Law, LexisNexis, pp. 470-471.

38 Estos criterios son destacados por un fallo de la Corte Suprema de Wyoming en Yates v. Yates. 702 P 2d 1251 y 1255 (Wyo. 1985).

De Witt / Swisher / Wolf (2005) 472.

39 California, Iowa, Maine, Oregon, etc.

40 De Witt / Swisher / Wolf (2005) 481.

41 D. Meyer, David (2005 - 2006): “The constitutional rights of non-custodial parents", en: Hofstra Law Review, p. 1473. 
en el Derecho americano ${ }^{42}$. Sin perjuicio de lo cual, a lo menos, ya existe un claro consenso en la separación entre $<<$ lo cotidiano $>>$, que puede ser conjunto o no, y los demás derechos y facultades que necesariamente son conjuntos. En este sentido se debe distinguir una custodia física del menor, que otorga al padre ciertos derechos y facultades inherentes a lo cotidiano, y otros aspectos que son necesariamente conjuntos y no dependen directamente de lo cotidiano. La delimitación de este imperceptible límite es de trascendental relevancia y su determinación es una de las labores fundamentales de los tribunales ${ }^{43}$. Por otra parte, también se ha desarrollado una forma de custodia compartida, conforme a la cual se busca incentivar conductas colaborativas de los padres con relación al niño, antes del quiebre. Esta forma de asignación ha sido propuesta por el $<<$ American Law Institute $>$, en sus $<<$ Principles of the Law of Family Dissolution $>>$, y han sido adoptada en $<<$ West Virginia $>>$. Esta forma de asignación ha sido denominada como $<<$ sharedparenting $>>$.

Como se ha podido apreciar el Derecho Comparado de la Infancia ha transitado desde un sistema de asignación unilateral de facultades y derechos de filiación a un sistema de ejercicio conjunto de facultades y derechos de filiación. Ello se ha debido a que una de las aplicaciones más relevantes del principio del interés superior del niño es la igualdad de los padres, por cuanto dicha aplicación asegura que los niños recibirán la formación y apoyo de ambos progenitores.

\section{3) MODIFICACIÓN DEL EJE DEL SISTEMA DE LA INFANCIA: COMPATI- BILIZACIÓN DE LOS PRINCIPIOS DE IGUALDAD DE LOS PADRES E INTERÉS SUPERIOR DEL NIÑO}

Las modificaciones anteriores se justifican en el cambio del eje del sistema de la infancia, que consiste en que el principio de la igualdad de los padres, no es sino una de las manifestaciones del principio del interés superior del niño ${ }^{44}$. El principio de la igualdad de los padres no solo afec-

42 A este respecto, Meyer agrega que la custodia compartida, como criterio de asignación legal, $(<<$ joint legal custody $>>)$ tiene las dos siguientes acepciones: poder de decisión conjunto y establecimiento alterno o compartido.

D. Meyer (2005 - 2006) 1470.

43 En este sentido es destacable un fallo de la Corte Suprema de New Jersey, que es del siguiente tenor: "[u]nder a joint custody arrangement legal custody -the legal authority and responsibility for making $<<$ major $>>$ decisions regarding the child's welfare- is shared at all times by both parents. Physical custody, the logistical arrangement whereby the parents share the companionship of the child and are responsible for $<<$ minor $>>$ day-today decisions, may be alternated in accordance with the needs of the parties and the children".

De Witt / Swisher / Wolf (2005) 480.

44 En este sentido se puede recordar el fallo de la $C I A D H$, de fecha 24 de febrero de 2012, contra el Estado de Chile, caratulado "Atala Riffo y niñas vs. Chile". La referida Corte, en el con- 
taría la asignación de las facultades y derechos de filiación -como sucedió en los ordenamientos jurídicos que establecían sistemas de asignación de facultades y derechos de filiación exclusivos, con facultades y derechos para el padre no custodio-, sino que vendría a determinar el contenido del ejercicio de las facultades y derechos de filiación de ambos padres. Así, el principio de la igualdad de los padres propende al desarrollo integral de los hijos. En efecto, el principio de la igualdad de los padres es una manifestación más del principio rector del Derecho de la Infancia, es decir, del interés superior del niño ${ }^{45}$. Como ya se pudo apreciar, el Derecho comparado, durante el último tiempo, ha establecido sistemas que propenden hacia una igualdad de facultades y derechos de los padres, dejando definitivamente atrás los sistemas de asignación exclusiva de derechos de filiación. En este sentido es posible consultar a un sinnúmero de autores, muchos de los cuales son tratados el presente artículo, que nos señalan que los derechos constitucionales del padre no custodio es una cuestión de trascendental importancia, que ha llevado a grupos de padre a asociarse y demandar al Estado por un trato igualitario y compatible con el interés superior del niño ${ }^{46}$. Este tema se ha querido llevar al campo de la lucha de sexos, pero es un tema transversal por cuanto si bien, en la

siderando $56^{\circ}$ de su fallo, entiende que la argumentación de la CS chilena -en torno a que la madre al hacer manifiesta su inclinación sexual "ha[bía] antepuesto sus propios intereses, postergando los de sus hijas", y configuraba una "<<situación de riesgo $>>$ que las ubicaba en un <<estado de vulnerabilidad en su medio social>>"- es discriminatorio. La CIADH concretamente va desechando una a una las alegaciones del Estado de Chile, respecto del interés superior del niño como sustento del fallo impugnado. Así, la CIADH señala que dicho interés debe apreciarse en concreto y que aún en caso que haya un daño a los hijos, producto de una reacción social contra los hijos por la inclinación de sus padres, no es admisible un fallo que se sustente sobre una discriminación. En este sentido, la CIADH en su considerando $121^{\circ}$ agrega que “...en cuanto al argumento de que el principio del interés superior del niño puede verse afectado por el riesgo de un rechazo por la sociedad, la Corte considera que un posible estigma social debido a la orientación sexual de la madre o el padre no puede considerarse un $<<$ dańo $>>$ válido a los efectos de la determinación del interés superior del niño. Si los jueces que analizan casos como el presente constatan la existencia de discriminación social es totalmente inadmisible legitimar esa discriminación con el argumento de proteger el interés superior del menor de edad. En el presente caso, el Tribunal resalta que, además, la señora Atala no tenía por qué sufrir las consecuencias de que en su comunidad presuntamente las niñas podrían haber sido discriminadas debido a su orientación sexual”.

Ver: http://www.corteidh.or.cr/docs/casos/articulos/seriec_239_esp.pdf (consultado el 9 de mayo del 2012).

45 A este respecto damos por establecido que el principio de igualdad de los padres y no discriminación de ninguno de ellos es un derecho fundamental, de acuerdo al ordenamiento jurídico chileno. Así se desprende de los artículos 1 y 19, No 2 de la CPE, 17.40 del Pacto de San José de Costa Rica (Convención Americana de Derechos del Hombre de 22 de noviembre de 1969) y 16, letras d) y f), de la Convención sobre la Eliminación de todas las Formas de Discriminación contra la Mujer.

46 En los Estados Unidos de América, bajo la $<<$ Rooker-Feldman doctrine $>$, se han entablado acciones indemnizatorias de clase contra los gobiernos Estatales por afectación de las facultades y derechos de los padres no custodio. Estas acciones no han prosperado por cuanto los Estados, han alegado la inmunidad de la Undécima Enmienda. En $<<$ Arnold $v$. Arnold $>>$ un padre alegó 
mayoría de los casos, la asignación unilateral del cuidado es a la madre, se está comenzado a otorga la custodia exclusiva también al padre. Por ello, la asignación y ejercicios de los derechos y facultades de filiación no es algo que deba ser abordado necesariamente desde la perspectiva de una lucha de sexos.

\section{1) LA NUEVA FAMILIA EN LA SOCIEDAD CHILENA}

La familia nuclear con padres casados entre sí e hijos, que viven con ellos, ha ido decreciendo en la mayoría de las sociedades europeas y latinoamericanas ${ }^{47}$. No es del caso hacer un análisis sociológico a este respecto, basta simplemente revisar las cifras ${ }^{48}$. Las estadísticas, en torno a los hijos nacidos fuera del matrimonio y el número creciente de padres ausentes, son alarmantes ${ }^{49}$. Ello se aprecia sobre todo si comparamos las cifras actuales con las altas tasas de hijos concebidos, durante el matrimonio, entre los ańos treinta y setenta ${ }^{50}$. Este proceso ha ido acompańado de

la violación de su derecho fundamental a tener, de forma igualitaria, a un hijo a su cuidado por cuanto de la totalidad del ańo el hijo solo estaba con su padre 102 días.

Algunas agrupaciones de padres han llegado a extremos en esta lucha por el reconocimiento de sus derechos civiles. Así, en el $R U$, uno de estos grupos, $<<$ fathers 4 justice $>>$, fue disuelto por la policía en medio de una trama para secuestrar a Leo Blair, hijo de cuatro años, del primer ministro de la época. La estrategia de la Agrupación, según los medios de comunicación, era llamar su atención (ver noticia en: http://www.thetimes.co.uk/tto/news/uk/article1950995.ece). D. Meyer (2005 - 2006) 1477 y 1462 [consultado el 6 de diciembre del 2012 en: http://lawarchive.hofstra.edu/pdf/academics/journals/lawreview/lrv_issues_v34n04_cc3_meyer_final.pdf]. Así uno de cada cinco hogares británicos está constituido por una familia nuclear (ver: http:// www.esds.ac.uk/government/vitals/datasets/ons/2001.asp). En Francia los padres solteros son un $50,5 \%$ de los padres al 2011, y la cifra va en aumento (INSEE, 2007). En Chile las cifras no difieren demasiado. Así por ejemplo Williams señala que de acuerdo a estadísticas del Instituto Nacional de Estadísticas (INE) en el 2005 aproximadamente 6 de cada 10 madres eran solteras en Chile.

Williams, Florence, "las jefas de hogar empobrecidas: servicios y recursos públicos para estas mujeres en Chile", p. 2 (ver en: http://digitalcollections.sit.edu/cgi/viewcontent. cgi?article=1863\&context=isp_collection) [consultado el 12 de diciembre del 2012].

48 En igual sentido PaLma nos señala que "[e]n todos los tramos de edad es posible ver un incremento de la proporción de nacimientos de hijos ilegítimos entre los ańos 1960 y 1990 (se refiere a los hijos no matrimoniales), situación que se acentúa en el caso que interesa para esta investigación, esto es, entre las el grupo de mujeres adolescentes y jóvenes. Entre las últimas, el porcentaje de ilegitimidad pasó de un 29,0\% a un 61,0\% en 30 años" (lo destacado entre paréntesis y cursiva es mío).

Palma Palma, Julieta (s.f.). "Familias adolescentes y jóvenes en Chile: cambios, a sincronías e impactos en sus formas de integración social”, en: Estudios de caso No 108, tesina de magíster en Gestión y Políticas Públicas de la Universidad de Chile, p. 19.

Ver en: http://www.mgpp.cl/wp-content/uploads/2011/04/CASO108.pdf [visitado 12 de diciembre del 2012].

49 Así, en la mayoría de los casos, es la madre soltera la que lleva a cabo la crianza de los hijos en Chile. De acuerdo al INE un 64,65\% de las madres estaban en esta condición el año 2008 (INE de Chile, 2008).

50 VALDÉs nos señala que la tasa de hijos nacidos fuera del matrimonio en los años sesenta llega a su piso histórico, un $16 \%$ de los hijos nacidos vivos. Y agrega que "[s]i pudo concebirse antes 
una creciente pérdida de la autoridad paterna, que se ha generado en dos etapas: (a) en una especie de Estado de Bienestar que se generó en Chile desde los gobiernos radicales y que duraría hasta los años setenta, y (b) en un proceso de desarticulación de la familia nuclear en el que estamos inmersos.

Un estudio empírico de VALDÉs da cuenta del fenómeno mediante el cual el padre ya no es exclusivamente el proveedor de la familia, sino que comparte dicho rol con la madre ${ }^{51}$. Además, este estudio es muy interesante porque de él se desprende que las mujeres suelen ser reticentes a ceder terreno en el hogar, lo que se complementa con que el mercado aún las discrimina remuneracionalmente ${ }^{52}$. Si bien la distribución de los roles en la familia se da en la realidad, ello ha generado problemas en las relaciones de pareja. Las parejas siguen distribuyéndose los roles en sus relaciones de familia, pero ya no lo hacen conforme a los cánones clásicos, y ello trae aparejada una fuerte tensión, que es multifuncional. Así, los

del proceso de industrialización a un <<padre ausente>> (Montecino, 1991), la errática figura paterna legada por el siglo XIX al siglo XX irá desperfilándose en favor del padre presente y responsable (VALDÉs, 2007), que trabaja y mantiene a su familia, en un contexto de altas tasas de fecundidad, nuclearización de la familia y de escasa participación laboral femenina”.

VALDÉs (2009) 389.

51 Una de las encuestadas señala que “[a]ntes los roles estaban definidos: el papá era el papá, el que traía las cosas a la casa. La mamá era la mamá y anda tú que le fueras a contestar a tu papá porque era complicado... porque lo que decía el papá era ley, ahora no. Por lo mismo las generaciones de hoy en día son distintas. Antes no, antes los papás tenían la razón y eran dueños de la verdad, ahora no. (F.C., 32 años, Ingeniero comercial, 2 hijos)”. A su vez, VALDÉs señala que las encuestas nos permiten distinguir tres modelos de padres: presentes y próximos (incluso algunos podrían definirse como domésticos), neopatriarcal y periféricos. A estos últimos padres, la autora los caracteriza como "...buenos proveedores y en su vida tienen gran importancia los éxitos laborales y el prestigio profesional. En lo cotidiano están poco presentes en la vida de sus hijos/as; dada su inclinación a desenvolverse en los espacios públicos no colaboran de manera activa en la crianza, aunque admiten que se sienten los trasmisores de valores y formadores y dicen tener una relación afectuosa con sus hijos".

VALDÉs (2009) 391 a 399.

52 En este sentido VALDÉs señala que "[s]in embargo, en este marco de transformaciones y de la aparición de nuevas concepciones de la paternidad suelen ser los padres separados -con y sin hijos a cargo- o aquellos con una frágil inscripción en el trabajo fuera de la casa, quienes mencionaron tareas domésticas tales como el aseo o la preparación de la comida, además de su inclusión en la crianza en las etapas tempranas de la niñez referidas más arriba. O, en el mismo grupo social, los separados que estimaron que mientras estuvieron con la madre de sus hijos su dedicación era completa, siendo excelentes padres, pero señalando que al mismo tiempo, $<<$ la loza podía dejarla dos días sin lavar y ella se ponía histérica > . Lo doméstico, en ese sentido continuaría siendo terreno exclusivo de la madre. De esta forma, emerge la duda respecto a afirmaciones que han pasado a ser casi un lugar común en la caracterización de la paternidad, como por ejemplo, que ahora los hombres son amorosos y afectuosos con sus hijos y sin embargo estos nuevos atributos por sí solos no cambian los tradicionales atributos maternos de cuidado y crianza, ya que es el hijo/a y la relación de filiación la que parece modificarse sin necesariamente modificar la trama de la división sexual del trabajo en la familia. Esto refuerza lo que encontramos en un estudio anterior basado en entrevistas a ambos miembros de la pareja (VALDÉs et al., 2006)".

VALDÉs (2009) 400. 
padres que pierden poder económico son recriminados por sus parejas y las madres al hacerse cargo de la casa y del trabajo fuera de ella, se sienten frustradas ${ }^{53}$. Lo anterior ha llevado a que los procesos de separación de los padres se estén multiplicando en la mayoría de nuestras sociedades. Ante ello es altamente conveniente preguntarse ¡cómo el Derecho puede ayudar, a las parejas que se han separado, a que uno de los padres no sea un progenitor o progenitora ausente?

\section{2) El MODELO REGULATORIO DEBERÍA HACERSE CARGO DE LAS NUEVAS FUNCIONES DE LOS PADRES, EN LA FAMILIA, A TRAVÉS DEL PRINCIPIO DE IGUALDAD Y LA EXPULSIÓN DE LA REGLA DE LA PREFERENCIA MATERNA.}

La función netamente asistencial, preponderante en el Derecho de Familia e Infancia chileno, no es suficiente para explicar toda la realidad. El Derecho debe hacer frente a dos situaciones que se dan con gran fuerza en Chile. Por una parte, hacerse cargo de las madres que educan solas a sus hijos (modelo protector de los hijos como de la madre y fuertemente asistencial), y por la otra permitir e incluso exigir que el padre tenga un rol relevante en la vida de sus hijos (modelo fundado en el interés superior del niño y la igualdad de los padres). Sin perjuicio de lo cual, a pesar que la madre, en la ruptura de la pareja, es la que se empobrece más, ya no cabe duda que también se produce un empobrecimiento en el padre ${ }^{54}$.

Como es natural una visión igualitaria del Derecho de la Infancia es incompatible con la denominada regla de la preferencia materna. Esta regla ha sido desechada en la mayoría de las legislaciones por reparos de constitucionalidad, dadas por la transgresión al principio de igualdad de

\footnotetext{
VALDÉS (2009) 400 y 401.

Los estudios de Lenore Weitzman, conocidos como 73/43, dieron origen a una extensa literatura sobre los efectos negativos de la separación y del divorcio en Estados Unidos de América respecto de las madres y favorable para los padres. Las consecuencias de dichos estudios se extenderían por el mundo entero. Las cifras del estudio de Weitzman arrojaban que el 73\% de las mujeres separadas, que se quedaban con los hijos, se veían perjudicadas con la separación o el divorcio y el $43 \%$ de los hombres se veían favorecidos. Dicho estudio fue la base de las políticas públicas del gobierno de Clinton. Sin embargo, en la actualidad los estudios de Weitzman están más que puestos en tela de juicio por graves fallas metodológicas, y son contradichos por la mayoría de las investigaciones que se han hecho sobre esta materia. Las cifras, aunque negativas para las mujeres separadas, son muy diferentes a las planteadas por WeITZMAN, siendo perjudicadas por la separación alrededor del $27 \%$ de las madres y mejorando su situación, después de la ruptura, aproximadamente el $10 \%$ de los padres. Incluso, la mayoría de los estudios que consideran "las necesidades de la familia" son muy vagos por cuanto no se basan en parámetros fiables como: el dominio del automóvil y del inmueble, que suelen repartirse por mitades después de la separación. Sin considerar que en la mayoría de los casos le corresponde a la madre el uso de los muebles o el usufructo del bien familiar y al padre o marido el pago del dividendo de dicho bien. En resumidas cuentas, lo que las estadísticas suelen reflejar es más bien una disminución patrimonial de la familia en su conjunto.
} 
los padres y no discriminación del padre. Sin embargo, esta regla subsiste en algunos países como regla de atribución legal supletoria. Una excepción parcial a esta regla adoptan los Derechos argentinos (la regla de la preferencia materna como asignación legal y supletoria se aplica a los hijos hasta la edad de cinco años) ${ }^{55}$ y alemán (que discriminaba al padre soltero).

El Derecho español, hace muchos años, dejó de lado esta regla. De este modo el ex artículo 159 del $C C E$ contemplaba una atribución directa del cuidado de los hijos menores de siete años a la madre, salvo que el juez por motivos especiales estableciera lo contrario. Este artículo fue modificado por la Ley No 11/1990, de 15 de octubre, señalándose como sustento de la expulsión de la preferencia materna del ordenamiento jurídico español por vía legal el principio de no discriminación por razones de sexo $^{56}$. Esta posición se ha asentado a tal grado, que ni siquiera se acepta como argumento a favor de otorgar el cuidado de los hijos pequeńos. En este sentido se puede consultar, la sentencia de la $A P$ de Baleares, de 29 de junio del 2005, que resuelve que “...en principio la guarda y custodia del hijo menor de edad puede ser atribuida tanto a la madre como al padre, sin que pueda existir trato preferencial hacia la una frente al otro. Ello no obsta para que, en la generalidad de los casos, durante la primera infancia y por el mayor contacto con la madres se tiende en la práctica a atribuirle a esta la guarda y custodia de los hijos".

Por otra parte, LATHROP se ocupa de este tema centrando la discusión en la determinación de sí es posible entender que el ex artículo 159 del CCE, en la redacción que le dio la Reforma de 1981, era discriminatorio, y por ende inconstitucional. La nueva redacción que le dio Ley No 11/1990 al ex artículo 159 del CCE entregó la decisión sobre el cuidado de los hijos al juez, sin supeditarla a la edad de los niños, tras oírlos, si tienen suficiente juicio, y, en todo, caso si fuesen mayores de doce años ${ }^{57}$. La mayoría de los autores en España estiman que el tratamiento igualitario de los padres obedece a un imperativo constitucional ${ }^{58}$.

55 Esta regla está a punto de modificarse en Argentina con la promulgación de un nuevo CC.

56 A favor de la constitucionalidad de la norma se indicaba que su objetivo era no separar a la madre de los hijos en la etapa de lactancia (<<tender years doctrine $>>)$, y no era fijar directamente un criterio de asignación de la guarda y custodia.

57 LATHROP agrega que esta Reforma no introduce ninguna originalidad a la forma de asignación del ejercicio de la patria potestad, por cuanto "[c] onforme al actual párrafo cuarto del art. 92 del CCE, los padres pueden acordar en el convenio regulador o el juez decidir, en beneficio de los hijos, que la patria potestad sea ejercida total o parcialmente por uno de los cónyuges".

58 De este modo, CARDEnal señala que la igualdad "se trata de una exigencia impuesta por la propia Constitución (art. 14) aunque, en atención al interés del menor, dispone de otros fundamentos diferentes de la no discriminación de los padres. Evidentemente, el propio interés del menor puede modular aquel principio, justificando la privación de la patria potestad o de su ejercicio a uno o ambos padres, total o parcialmente, o un reparto desigual de las funciones atribuidas". 
En Estados Unidos de América, conforme a lo ya analizado, la regla de la $<<$ tender years presupmption $>>$ ha sido totalmente suprimida.

En el Derecho Alemán uno de los fallos más relevantes, en torno a la igualdad y no discriminación de los padres, es el pronunciado por el TEDH, de fecha 3 de diciembre del 2009, en los autos "Zaunegger v. Germany" (no. 22028/04). El TEDH condenó al Estado Alemán por discriminar entre los hijos matrimoniales y no matrimoniales respecto de la asignación de derechos de paternidad. En esta causa, el padre de una menor, Horst Zaunegger, recurre al TEDH contra la decisión de los tribunales alemanes, que aplicando correctamente el $B G B$, no le concedieron la custodia compartida de su hija, que había vivido con él entre 1995 y junio del 2001. Tanto las sentencias de instancia (Corte de Distrito de Colonia y de Apelaciones), como la sentencia del $T C$ alemán desecharon su demanda de custodia compartida. El padre, en consideración a ello, recurrió ante el TEDH, aduciendo que los tribunales alemanes habían violado su derecho a la vida familiar y lo habían discriminado por el hecho de ser soltero ${ }^{59}$. La Corte, acogiendo el recurso, condenó al Estado alemán por cuanto el $\$ 1626 \mathrm{a}, \mathrm{n}^{\circ} 1$ del $B G B$ infringía los artículos 14 y

Cardenal, Rafael (2011): “Tema 16. Patria potestad”, en: Tomo I. Parte Sustantiva. Los 25 temas más frecuentes en la vida práctica del derecho de familia, Lledó YaGüE, Francisco, SÁnCHez Sánchez, Alicia (directores), Monje Balmaseda, Oscar (coord.), p. 439; Linacero de la Fuente, María Asunción (1990): "Acerca de la Posible Inconstitucionalidad del artículo 159 del Código Civil", en: Revista de Derecho Privado, julio-agosto, Editorial Revista de Derecho Privado, Madrid, pp. 561 a 582 y Lathrop Gómez, Fabiola (2008). Custodia compartida de los hijos, La Ley, Madrid, España, p. 96. En Chile entienden que es inconstitucional la regla de la preferencia materna, Gómez de la Torre y LATHrop Gómez.

En igual sentido se inclina Delgado Del Río, señalando que: " $<<\ldots$ no existe en nuestro ordenamiento jurídico una suerte de presunción de idoneidad -en cuanto a la guarda y custodia de los hijos- que juegue a favor de alguno de los progenitores, pues en principio tanto el padre como la madre están igualmente capacitados para atender de modo conveniente a los hijos, sin que pueda apriorísticamente afirmarse que alguno de ellos posee mejores condiciones naturales para cuidar de la prole» (AP Alicante, s. 16.05.2007, SP/SENT/129717. Cfr. AP Alicante, s. 8.05.2006, SP/SENT/ 98031. Cfr. Domínguez Castellano, La guarda..., cit., pg. 16, SP/ DOCT/ 2836) de ambos (Erich Fromm, El arte..., cit., págs. 49-50), aunque, de modo diferente, en función de la edad.

Esta toma de posición me parece, desde una perspectiva jurídica, intachable y, a la vez, muy exigente. Tiene, a mi entender, un claro apoyo sicológico y/o psiquiátrico. Su aceptación obliga a todos a desterrar viejas ideas y concepciones, que ya tienen muy poco que ver con la concepción actual de la familia y con las respectivas funciones simbólicas que en ella están llamados a desempeñar el hombre y la mujer, tanto antes como después de la ruptura de su convivencia (Cfr. Domínguez Castellano, La guarda..., cit., pg. 17, SP/DOCT/2836; Erich Fromm, l.c.)".

Delgado del Río (2010): La Custodia de los hijos. La guarda compartida: opción preferente, Thomson Reuters, Civitas, Navarra, España, p. 45.

59 Morell, Ana (2010): "La posición del tribunal europeo de derechos humanos sobre la custodia compartida de hijos no matrimoniales", en: Revista de Derecho de Familia No 2, Abeledo Perrot, Santiago de Chile, junio, p. 242. 
18 de la Convención Europea de Derechos Humanos ${ }^{60}$. En cumplimiento del referido fallo una sentencia del TC alemán, de fecha 21 de julio del 2010 , vendría a modificar en parte este panorama, al resolver que, mientras se modifica la norma impugnada por el Senado, la custodia compartida se puede conceder a los padres no matrimoniales, complementando lo establecido en el $\mathbb{S} 1626 \mathrm{a}, \mathrm{n}^{\circ} 1$ del $B G B$ de acuerdo al interés superior del nińo y no exigiendo requisitos -sobre todo de admisibilidad de la custodia compartida- que no hagan posible dicha posibilidad. El fallo resolvió, que de acuerdo a las reglas generales, también es posible repartir las facultades y derechos de filiación entre los padres o si se hace imposible la custodia compartida, otorgársela al padre de forma provisoria ${ }^{61}$. Final-

60 Los argumentos fueron los siguientes:

a) La atribución exclusiva del cuidado a la madre, respecto de los hijos no matrimoniales, de acuerdo al bienestar del menor, establecido en el $\$ 1626 \mathrm{a}, \mathrm{n}^{\circ} 1$ del $B G B$ era desproporcionado y excesivo.

b) Se desechó el argumento aducido por el Estado alemán en torno a suponer que la custodia no puede ser compartida en caso de los padres solteros por cuanto respecto de ellos la relación sería más confrontacional con la madre.

c) Los padres tienen derecho a que la asignación legal de la custodia sea revisada por los tribunales y sea otorgada la custodia compartida. Lo que la Corte encontró poco razonable es impedir que los padres solteros no tuvieran acceso a los tribunales para solicitar la custodia comparti$\mathrm{da}$, de acuerdo al interés superior del niño, con oposición de la madre.

Así, el TEDH resolvió que "...that there might also be sound reasons for refusing an unmarried father the right to share parental custody. This might be the case if disputes or a lack of communication between the parents endangered the child's best interests. However, it was by no means proved that the relations between unmarried fathers and their children were generally characterized by such an attitude. If there were no sound reasons, then under \$ 1626a.1 no. 1 of the Civil Code the father of a child born out of wedlock was nevertheless from the outset deprived by law of the opportunity to apply for a judicial review as to whether the transfer of joint parental custody would serve the child's best interests, and to initiate legal proceedings to obtain surrogate consent, where the refusal of the mother to consent to joint parental custody might be arbitrary. The argument of the legislature was unconvincing that if the parents lived together but the mother refused to make a joint declaration of parental custody this was an exception to the rule and the mother had serious reasons for this which were based on the child's best interests".

Ver en: http://www.bverfg.de/entscheidungen/rs20100721 1bvr042009en.html [sitio visitado el 13 de diciembre del 2012].

61 El párrafo 75 del considerando III, de la parte resolutiva del fallo del TC alemán, se refiere a la custodia compartida en los siguientes términos: "[i]t therefore appears appropriate to proceed from the present legislative concept of the legislature, which makes the establishment of joint parental custody of parents of children born out of wedlock dependent on making joint declarations of parental custody. Consequently, supplementing this provision of $\$ 1626$ a.1 no. 1 of the Civil Code, it is provisionally ordered, until revised legislation enters into effect, that the Family Court, on the application of one parent, shall transfer parental custody or part of parental custody to the parents jointly, provided it is to be expected that this is in the child's best interests. The selected standard of review of the child's best interests is intended to ensure that the concerns of the child are taken decisively into account, but the requirements for access to joint parental custody are not made too stringent”. A su vez, el párrafo 76, del mismo considerando, se refiere a la posibilidad de repartir o otorgar el cuidado personal al padre en los siguientes términos: "[w]ith regard to the transfer of sole custody to the father, an appropriate arrangement for the transitional period until the reform of the law would follow the provision 
mente, el 31 de enero de 2013 se publicó la Ley modificatoria de la nueva regla de la custodia de progenitores no casados, que entró a regir el 19 de mayo de 2013. A futuro los padres pueden incluso contra la voluntad de la madre solicitar la custodia; cuando con ello no transgreda el interés del menor. Todo esto es en respuesta a la inconstitucionalidad del parágrafo 1626 a $B G B$.

En cuanto a la asignación de los derechos de filiación, conforme a la regla de la preferencia materna en Chile, Gómez DE LA TORRE considera, al igual que lo haría el $T C$ chileno en un fallo posterior ${ }^{62}$, que lo que es inconstitucional es entender que el interés superior del niños se traduce en la regla de la preferencia materna, y que de este modo primaría esta forma tan peculiar de comprender el interés superior del niño sobre el principio de igualdad. Y, a este respecto, agrega que "[l]a interpretación restrictiva del at. 225 es anticonstitucional, porque transgrede la garantía constitucional de la igualdad (art. 19, N 1 Constitución), al discriminar arbitrariamente al padre. Viola también los arts. 17.4 de la Convención Americana sobre Derechos Humanos (hay nota al pie) y el art. 16, d y f, de la Convención sobre la Eliminación de todas las Formas contra Discriminación de la Mujer"63. En igual sentido para LATHROP la regla de la

of $\int 1671$ of the Civil Code. Since this provision also requires that the transfer of sole parental custody is to be made only if the requirements for joint parental custody of the parents are no longer satisfied, and at the same time, as set out under B.II.5.b) (4), the establishment of joint parental custody where the mother previously had sole parental custody is less detrimental to her parental right than a complete change of parental custody from herself to the father, then in supplementation of $\int 1672.1$ of the Civil Code, until a reform of the law enters into effect it is provisionally ordered that the Family Court, on the application of a parent, shall transfer to the father the parental custody or part of the parental custody where joint parental custody is out of the question and it is to be expected that this best serves the child's best interests".

Ver: BVerfG, 1 BvR 420/09 vom 21.7.2010, Absatz-Nr. (1 - 78), en: http://www.bverfg.de/ entscheidungen/rs20100721 1bvr042009.html [sitio visitado el 13 de diciembre del 2012].

En este sentido, en la causa Rol 1515-09-INA, pronunciada por la Primera Sala del TC, integrada por su ex Presidente, Marcelo Venegas Palacios, y los Ministros señores José Luis Cea Egaña, Mario Fernández Baeza, Marisol Peña Torres y Francisco Fernández Fredes, se resuelve, en su considerando décimo, que “...parece contradictorio el requerimiento interpuesto y, por ende, carente de fundamento razonable, si lo que este persigue es que, por efecto de la sentencia que dicte esta Magistratura Constitucional, acogiendo la acción, se impida al juez que conoce de la causa sub lite aplicar precisamente la norma legal cuestionada, en circunstancias de que es ella la que hace posible que se entregue el cuidado del respectivo hijo menor a cualquiera de los padres que acredite ante el respectivo tribunal-cuando no existe el acuerdo de que trata el inciso segundo de la disposición - ser el más idóneo para ello, según se ha indicado" (lo destacado en cursiva es mío).

Disponible en (consultada el 14 de enero del 2011): http://www.tribunalconstitucional.cl/index.php/sentencias/download/pdf/1272.

63 Sara Rodríguez se inclina a favor de la constitucionalidad de la regla de la preferencia materna, pero reconoce la conveniencia de modificarla. En lo que toca a su constitucionalidad, la referida autora señala que "[r]ecapitulando, entonces, puede afirmarse que las objeciones de constitucionalidad de la preferencia materna no pueden apoyarse en la regla constitucional que prohíbe diferencias arbitrarias: es una regla supletoria de la voluntad de los padres que no confiere a la madre derecho subjetivo alguno, sino una función o un deber de la que no está privado el padre 
preferencia materna sacrifica la igualdad del padre, sin cumplir con el test de razonabilidad, ni de proporcionalidad, infringiéndose de este modo el artículo 19, no 2 CPE, y los tratados sobre igualdad de género suscritos por Chile (Convención sobre la Eliminación de todas las Formas de Discriminación contra la Mujer). Para LATHROP se estaría alterando la igualdad material de la mujer al estereotiparse los roles en la familia, al considerarse al padre como el proveedor y la madre como la encargada de los hijos y del hogar ${ }^{64}$. Por otra parte, la férrea oposición a la inconstitucionalidad del artículo $225.1^{\circ}$ y $3^{\circ}$ del $C C C h$, por parte del TC chileno, ha venido resquebrajándose ${ }^{65}$.

y que no impide la modificación judicial de la atribución legal en función del interés del niño. La preferencia materna tampoco ofende el interés del hijo.

Al contrario, evita litigios y la excesiva judicialización de los conflictos de los padres sobre el cuidado personal de sus hijos y favorece los acuerdos. Todo lo cual no quiere decir que esta regla no admita otras formulaciones, como las que existieron en el Derecho chileno hasta la reforma de la Ley 18.802 de 1989 ".

Rodríguez Pinto, María Sara (2009): "El Cuidado Personal de Niños y Adolescentes en la Familia Separada: Criterios de Resolución de Conflictos de Intereses entre Padres e Hijos en el Nuevo Derecho Chileno de Familia”, en: Revista Chilena de Derecho, vol. 36, núm. 3, p. 564.

Gómez de la Torre, Maricruz (2008): "El nuevo derecho de la niñez", en: Estudios de Derecho

Privado, Libro Homenaje al profesor Gonzalo Figueroa Yáñez, Editorial Jurídica de Chile, Santiago de Chile, p. 447 y Lathrop Gómez, Fabiola (2010): "(In)constitucionalidad de la regla de atribución preferente materna del cuidado personal de los hijos del artículo 225 del código civil chileno", en: Revista Ius et Praxis, Año 16, nº 2, pp. 147 a 184.

65 Así, en un fallo del TC chileno, de veinte de noviembre de dos mil doce, aunque la posición mayoritaria del tribunal no varía, se presentan importantes votos disidentes que estuvieron a favor del requerimiento por inconstitucionalidad contra el artículo $225.1^{\circ}$ y $3^{\circ}$ del CCCh. Dichos votos minoritarios fueron presentados por una parte del ministro Raúl Bertelsen y por la otra, por los ministros Marcelo Venegas y José Antonio Viera-Gallo. El primero de los votos disidentes señaló, en el considerando $3^{\circ}$, que la regla de atribución del cuidado personal al padre contenida en el artículo $225.3^{\circ}$ del $C C C h$ "resulta excesivamente onerosa y desproporcionada pues exige la ocurrencia de circunstancias tan altas y calificadas que constituyen una diferencia de trato que cabe calificar de arbitraria y que no tiene amparo en la Constitución"; agregando que la referencia a que la asignación al padre sea indispensable para el interés del hijo, pero en atención al únicamente por maltrato, descuido u otra causa calificada "impide al juez, si no concurren estas circunstancias, confiar al padre el cuidado de los hijos aunque fuere simplemente beneficioso de acuerdo a las circunstancias del caso" para, finalmente, en el considerando $4^{\circ}$, resolver que "tal diferencia de trato entre el padre y la madre, excede lo que es lícito hacer al legislador conforme a la garantía constitucional de igualdad ante la ley, puesto que no puede calificarse de razonable o justificada, máxime si la Carta Fundamental, específicamente señala que $<<$ hombres y mujeres son iguales ante la ley>>, por todo lo cual debiera declararse la inaplicabilidad de la norma impugnada". El segundo voto disidente, de los ministros Marcelo Venegas y José Antonio Viera-Gallo, en su considerando $12^{\circ}$ falla que "esta regla de atribución judicial del cuidado de los hijos de padres separados, aunque declara velar por el interés del niño, en la práctica exige para su aplicación atender a consideraciones de otra naturaleza: Primero, a una virtual inhabilitación moral del padre o madre que perderá el cuidado, pues habrá de acreditarse que hubo, de su parte, maltrato, descuido u otra causa calificada que haga indispensable la separación de su hijo. Y luego, escrutar si el padre o madre que ahora puede ofrecer buen trato y cuidado al niño en peligro, contribuyó o no a la mantención del hijo mientras estuvo al cuidado del otro padre, pudiendo hacerlo", y agrega, en el considerando $13^{\circ}$, que "[n]o solo es inconstitucional, sino que resulta contraria al sentido común una regla que, supuestamente 
Sin perjuicio de lo anterior, existen algunos autores que sostienen que la asignación del cuidado personal y regulación del contenido del cuidado personal debe hacerse conforme al interés superior del niño, aplicando adecuadamente las facultades que la ley otorga al juez y los principios que se incorporan al Derecho de la Infancia, conforme a la $L M C$ y $L T F$. Lo anterior permitiría interpretar adecuadamente las reglas del artículo $225.1^{\circ}$ y $3^{\circ}$ del $C C C h^{66}$.

En definitiva, dado el análisis precedente, nos inclinamos a favor de la expulsión de la regla de la preferencia materna del ordenamiento jurídico. A pesar que la Corte Suprema acertadamente ha reinterpretado esta regla ella es incompatible con el principio del interés del niño ${ }^{67}$. Así, un

concebida para proteger el interés del niño, lleva, en la práctica, al extremo de obligar a un padre a invocar la inhabilidad moral de la madre de su hijo, como único motivo plausible para obtener la custodia del niño, cuando cree que estará mejor a su cuidado (...) Una regla que lleva a este extremo no solo es contraria a la igualdad sino que atenta contra la dignidad humana y, por cierto, en contra del interés superior del niño". Como sustento del precedente voto de minoría se citan los artículos $3.1^{\circ}, 9$ y 12 de la $C D N, 16$ de la $L T F$ e incluso sentencias del propio $T C$ chileno referente al interés superior del niño como principio medular del ordenamiento jurídico (roles n 465, 786, 1537, 1656 y 1683).

Ver: http://www.tribunalconstitucional.cl/wp/ver.php?id=2593

66 Acuña, a este respecto, plantea la siguiente opinión: “[c]omo se ha explicado, en caso de divorcio la LMC entrega facultades decisorias al juez, cada vez que no se produce acuerdo entre los progenitores sobre el cuidado personal de los hijos. Las diversas normas que con carácter provisional definitivo exigen el pronunciamiento judicial no ofrecen orientaciones específicas para esta decisión, aunque sí proporcionan principios claros sobre los cuales se debe fundamentar la concreta solución: cuidar proteger siempre el interés de los hijos y oir a aquel que esté en condiciones de formarse un juicio propio, teniéndose debidamente en cuenta sus opiniones, en función de su edad y madurez. A partir de ahí, el juez de familia goza de bastante amplitud en la materia, pudiendo otorgar el cuidado personal a la madre o al padre respecto de todos o algunos de los hijos menores, discriminando en función de sexo y/o edad o circunstancias especiales de los menores o de condiciones personales o materiales de los progenitores; podría también establecer un ejercicio sucesivo del cuidado personal por tiempos determinados para uno y, luego, para el otro progenitor, así podría establecer que toca el cuidado personal a la madre durante la primera edad de los niños y luego tocará exclusivamente al padre. Todas estas medidas podrán modificarse si se da causa para ello, esto es, si así lo demanda el interés superior de los hijos, entendido en su sentido positivo (búsqueda de su óptimo beneficio) y negativo (evitación de los riesgos o peligros)".

A su vez, BARCIA sostiene que deben redefinirse las categorías de autoridad parental y cuidado personal, a la luz del principio del interés superior del niño, de tal forma de distinguir entre facultades y derechos conjuntos, exclusivos para el padre custodio y exclusivos para el padre no custodio

Acuña San Martín, Marcela (2011): Efectos jurídicos del divorcio, Abeledo Perrot y Thomson Reuters, Santiago de Chile, pp. 386 a 392 y Barcia Lehmann, R. (2011). Fundamentos del Derecho de Familia e Infancia, Editorial Thomon, Santiago de Chile, pp. 468 a 504.

La Corte Suprema ha desechado la aplicación del artículo $225.3^{\circ}$ del CCCh, conforme a los artículos 226 del CCCh y 42 de la $L P M$, permitiendo que no se aplique por resolución judicial la regla de la preferencia materna y optando por el padre, pero solo en los casos en que los cuidados de la madre hacen peligrar física o emocionalmente al niño.

Ver: Barrientos Zamorano, Marcelo, (2012): “¿Es interés superior o inferior del niño. Aplicación jurisprudencial del artículo 42 de la Ley de Menores a la luz del Código Civil”, en: Estudios de Derecho Civil VII (X Jornadas de Derecho Civil), Viña del Mar [Elorriaga De Bonis, Fabián], Abeledo Perrot, LegalPublishing Chile y Thomson Reuters, Santiago de Chile, pp. 117 a 126; Lathrop Gómez (2010) 151 y Barcia Lehmann, R. (2012): "Una Mirada al 
criterio de esta clase, establecido de forma $<<$ per se>>, es contrario al interés superior del nińo y fija nefastos incentivos en torno a la adopción de un sistema de cuidado personal unilateral, que respete al padre o madre no custodio. Además, dicha regla es absolutamente incompatible con un sistema que tenga como objetivo equilibrar las facultades y derechos de los padres en beneficio del hijo.

Finalmente, como se verá, el Proyecto de reforma de cuidado personal en su actual redacción, acertadamente, expulsa la regla de la preferencia materna del ordenamiento jurídico chileno.

\section{4) VALORACIÓN DEL SISTEMA CHILENO DE ASIGNACIÓN DE FACULTA- DES Y DERECHOS DE FILIACIÓN EN CASO DE SEPARACIÓN DE LOS PADRES A LA LUZ DEL DERECHO COMPARADO}

A continuación se evaluarán los incentivos que el sistema chileno de asignación exclusiva de facultades y derechos de filiación a favor de la madre crea y la forma en que el Proyecto de Reforma sobre cuidado personal abordada la regla de la preferencia materia y el ejercicio conjunto de facultades y derechos por los padres.

\section{1) INCENTIVOS DEL ACTUAL SISTEMA DE ASIGNACIÓN DE FACULTA- DES Y DERECHOS DE FILIACIÓN}

La deficiencia de la regulación chilena actual se puede apreciar en el cuadro que está signado con el número 1. Dicho cuadro representa un juego en el que existen tres jugadores: la madre (primer casillero), el padre (segundo casillero) y el hijo (tercer casillero). En los cuatro cuadros se puede apreciar las distintas estrategias negociadoras que se pueden dar, de acuerdo a la actitud de cooperar de cada jugador con relación a los otros jugadores. Si ambos padres quieren tener el cuidado personal del hijo, y el Derecho -como sucede en Chile- asigna el cuidado personal a la madre, este sería el resultado en la mayoría de los casos: En el supuesto que ambos padres cooperen se produce el máximo beneficio social por cuanto en esta situación todos ganan, la suma de 6 (casillero superior izquierdo), lo que genera un beneficio social de 18. Sin embargo, como el acuerdo supone una motivación racional y que el Derecho asigna el cuidado personal a la madre, ¿qué le llevará a acceder a negociar un acuerdo de cuidado conjun-

Cuidado Personal, y en especial a los artículos 224, 225.1ํ y $3^{\circ}$ del Código Civil y 42 de la Ley de Protección de Menores, desde la perspectiva del Interés superior del Niño”, en: Estudios de Derecho Civil VII (X Jornadas de Derecho Civil), Viña del Mar [Elorriaga De Bonis, Fabián], AbeledoPerrot, Legal Publishing Chile y Thomson Reuters, Santiago de Chile, pp. 127 a 145. Gómez (2008) 458 y Lathrop (2008) 464; Acuña (2011) 468 a 504. 
to, de distribución de facultades u otorgamiento de facultades respecto del padre? Lo racional sería entonces que se diera lo que se denomina $<<$ nash equilibrio >> o equilibrios no óptimos. En dicho escenario sí el padre coopera con la madre y el hijo, a pesar de no tener derecho alguno, se obtiene un beneficio social de 2. En este escenario, que estaría representado por el cuadro inferior izquierdo, el hijo no pierde del todo, pero no tiene al padre que podría tener, sino solo al padre que su madre le permitirá por lo que le asignamos un valor que puede ir de 0 a $6(+1)$. Es muy probable que el valor social que se obtenga será más bien una asignación baja por cuanto el padre solo podrá operar conforme a los rangos que el Derecho le permita (lo que se traduciría concretamente en visitas por cuatro días al mes ${ }^{68}$. El escenario en el cual el padre no coopera con la madre, que sí lo hace, supone un padre que no está interesado por su hijo.

En este supuesto solo se obtendrá como beneficio social las exigencias que pueda imponer la madre respaldada por el Derecho, como conseguir alimentos. Por ello es tan importante que los deberes y obligaciones de la filiación sean ejecutables.

Por último, el escenario en que ninguno de los padres coopera con el otro, es sumamente probable, ya que la madre no tiene incentivos para cooperar y el padre como no tiene una verdadera relación de filiación con su hijo. Este padre en el largo plazo no cooperará, generándose una pérdida social de -12 , este es el escenario más probable, y es el que se da en muchas familias chilenas.

\section{CUADRO No 1}

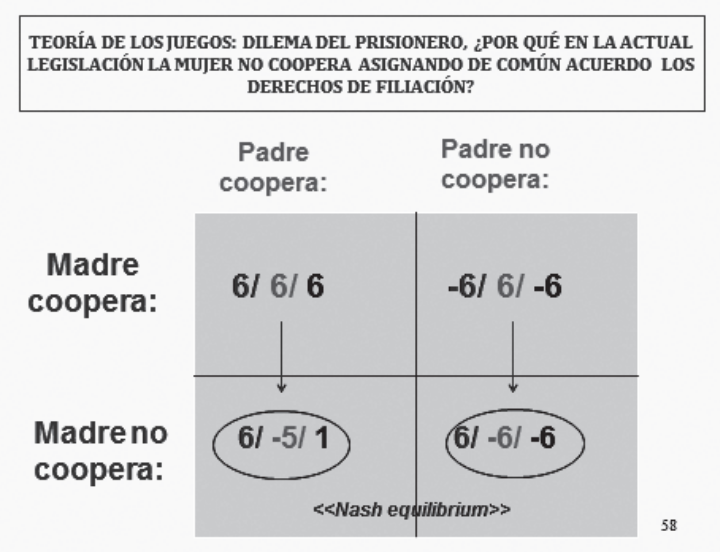

68 En realidad el escenario en Chile es un poco más dramático por cuanto una parte de la doctrina ha entendido que los padres no pueden celebrar un acuerdo de cuidado compartido. Si ello es de esta forma entonces se cierra el círculo y la madre jamás procederá a negociar un acuerdo de cuidado compartido, igual solución que se impondrá respecto del acuerdo de distribución de funciones, como sí el padre se ocupa de la educación religiosa y la madre de los resultados en el colegio. 


\section{2) EL PROYECTO DE REFORMA DEL CUIDADO PERSONAL: EXPUL- SIÓN DE LA REGLA DE LA PREFERENCIA MATERNA, EL INTERÉS SUPERIOR DEL NIÑO Y LA CUSTODIA COMPARTIDA}

a. El Proyecto originalmente mantenía la regla de $<<$ la preferencia materna >>, pero solo como un criterio de asignación legal supletorio y establecía como criterio de asignación judicial del cuidado personal el interés superior del niño ${ }^{69}$. En el Senado y en la Comisión Mixta se optó por mantener como regla de asignación judicial del cuidado personal al interés superior del niño. Sin embargo se expulsó como regla legal supletoria a la superioridad materna, asignando el cuidado personal al padre o madre que resida con el menor ${ }^{70}$. El que el cuidado personal, mientras el juez decide, quede en poder de quien efectivamente ejerza dicho cuidado es sumamente acertado. Además, esa era la tendencia prevaleciente en nuestra jurisprudencia ${ }^{71}$.

69 El artículo $225.3^{\circ}$ y $4^{\circ}$ del CCCh aún se discute en la Comisión Mixta del Congreso; pero en su actual redacción, consensuada al 17 de mayo del 2013 entre varios profesores de Derecho Civil (Lathrop, Lepín, Domínguez y Rodríguez), la Jueza Negroni y el SERNAM, se establece lo siguiente: “[a] falta del acuerdo del inciso primero, los hijos continuarán bajo el cuidado personal del padre o madre con quien estén conviviendo.

En cualquiera de los casos establecidos en este artículo, cuando las circunstancias lo requieran y el interés superior del hijo lo haga conveniente, el juez podrá atribuir el cuidado personal del hijo al otro de los padres, o radicarlo en uno solo de ellos, si por acuerdo existiere alguna forma de ejercicio compartido".

70 El borrador de artículo $225.3^{\circ}$ del CCCh establece la regla de asignación legal supletoria. En la redacción que a esta regla se le dio en el Senado establecía: "[s]i los padres viven separados (...) y mientras no exista acuerdo, el juez deberá resolver dentro de 60 días quién tendrá a cargo el cuidado del hijo. En el intertanto, éste continuará bajo el cuidado de la persona con quien esté residiendo, sea este el padre, la madre, o un tercero".

Sin perjuicio de ello, como ya se vio en la Comisión Mixta se está discutiendo si dejar fuera tanto la referencia a los sesenta días, como la posibilidad que un tercero ejerza momentáneamente el cuidado personal.

71 Lo señalado se sustenta en un estudio exhaustivo de los fallos pronunciado por los tribunales superiores de justicia, restringido al segundo semestre del año 2010, elaborado por UNICEF (Rodrigo Barcia Lehmann, Director, y Lennon González, Viviane y Garcés Sepúlveda, Félix, investigadores).

Ver fallos de la CS, de fecha dieciocho de noviembre de dos mil diez, Rol No 5.770 - 2010, RIT No 975-2008 y de la CA de Santiago, de fecha nueve de noviembre de dos mil diez, Rol No $821-2010$.

La primera sentencia de la CS resuelve que la regla de atribución del cuidado personal en caso de que los padres vivan separados, que establece una preferencia por la madre, solo puede ser modificada en la medida que exista una causa justificada y que el interés del menor lo exija, lo que sí ocurre en el caso de autos, en donde el contexto familiar en el que vive el menor con su padre parece ser lo que más enmarca con su mejor desarrollo y bienestar en consonancia con el interés superior del menor. La segunda de las sentencias citadas resuelve, en su considerando sexto, que "en cuanto al cuidado personal que de la hija común de las partes que la sentencia entrega a la madre, tal decisión será revocada, teniendo en cuenta que el padre ha tenido ininterrumpidamente dicho cuidado personal desde hace tres ańos, sin que exista en autos manifestación probatoria alguna en cuanto a que dicho cuidado no lo haya sido del modo conveniente y acorde con el interés superior de la menor. al contrario, alterar su situación actual para llevarla 
b. El Proyecto asigna de forma unilateral el cuidado personal a uno de los padres, estableciendo además criterios claros para asignarlo conforme al interés superior del niño ${ }^{72}$. De este modo, la asignación del cuidado personal es igualitaria y, en principio, atiende al interés superior del niño.

c. Como contrapartida a la asignación unilateral del cuidado personal, respecto del padre no custodio, el Proyecto, en su actual redacción, reconoce facultades y derechos conjuntos para ambos padres, que se desprenden de la corresponsabilidad parental, y que son la crianza y educación de los hijos $^{73}$; pero además establece criterios claros de configuración de la relación directa y regular respecto del padre no custodio.

d. El Proyecto solo se refiere al cuidado compartido de común acuerdo entre los padres en la propuesta de modificación del artículo $225.1^{\circ}$ y $2^{\circ}$ del $C C C h^{74}$. En dicha regulación se dejó fuera del Proyecto ori-

a un ambiente diverso podría redundar en un perjuicio a su actual desarrollo físico, psíquico y emocional, además de alterar perjudicialmente las relaciones de armónico cuidado que la familia paterna también actualmente le proporciona, y de alterar incluso su estado y rendimiento escolar, lo que no aparece de modo alguno compatible con ese interés superior que la ley ha tratado de tutelar tan superlativamente en diversas disposiciones legales, como por ejemplo en el artículo 16 de la Ley $\mathrm{N}^{\circ} 19.968$, según el cual el interés superior del niño es un principio rector que el juez de familia debe tener siempre como consideración principal en la resolución del asunto que a su respecto fuere sometido a su conocimiento".

Ver: http://www.unicef.cl/uniceffamilia/

72 El nuevo artículo $225-2^{\circ}$ del CCCh, propuesto por el Senado y que actualmente está en Comisión Mixta, señala que "[e]n el establecimiento del régimen y ejercicio del cuidado personal, se considerarán y ponderarán conjuntamente los siguientes criterios y circunstancias:

a) La vinculación afectiva entre el hijo y sus padres, y demás personas de su entorno familiar;

b) La aptitud de los padres para garantizar el bienestar del hijo y la posibilidad de procurarle un entorno adecuado, según su edad;

c) La actitud de cada uno de los padres para cooperar con el otro, a fin de asegurar la máxima estabilidad al hijo y garantizar la relación directa y regular;

d) La dedicación efectiva que cada uno de los padres procuraba al hijo antes de la separación y, especialmente, la que pueda seguir desarrollando de acuerdo con sus posibilidades;

e) La opinión expresada por el hijo;

f) El resultado de los informes periciales que se haya ordenado practicar;

g) Los acuerdos de los padres antes y durante el respectivo juicio;

h) El domicilio de los padres, e

i) Cualquier otro antecedente que sea relevante atendido el interés superior del hijo".

73 En este sentido el nuevo artículo $224.1^{\circ}$ del CCCh, propuesto por el Senado y que actualmente está en Comisión Mixta, señala "[t]oca de consuno a los padres, o al padre o madre sobreviviente, el cuidado personal de sus hijos. Este se basará en el principio de corresponsabilidad, en virtud del cual ambos padres, vivan juntos o separados, participarán en forma activa, equitativa y permanente en la crianza y educación de sus hijos".

74 El artículo $225.1^{\circ}$ y $2^{\circ}$ del CCCh, aún se discute, en la Comisión Mixta del Congreso; pero en su actual redacción, consensuada al 17 de mayo del 2013 entre varios profesores de Derecho civil (Lathrop, Lepín, Domínguez y Rodríguez), la Jueza Negroni y el SERNAM, se establece lo siguiente: " $[\mathrm{s}] \mathrm{i}$ los padres viven separados podrán determinar de común acuerdo que el cuidado personal de los hijos corresponda al padre, a la madre o a ambos en forma compartida. $\mathrm{El}$ acuerdo se otorgará por escritura pública o acta extendida ante cualquier oficial del Registro 
ginal la exigencia de autorización del juez que además debía velar por la concurrencia de una serie de requisitos 75 .

e. Lamentablemente, la Reforma no hace referencia a la posibilidad de dar lugar a la custodia compartida por orden judicial con oposición de uno de los padres.

f. La regulación, aunque adecuada, no se condice con la actual legislación comparada, y creará incentivos a aumentar la litigiosidad, a lo menos respecto de los padres que se encuentran excluidos de las facultades y derechos de la filiación. Sin perjuicio de lo cual, el sistema propuesto podría ser un comienzo adecuado para aplicarse a nuevas parejas, que preferirán llegar a acuerdos antes que el juez asigne el cuidado personal a uno de ellos con exclusión del otro.

\section{PRincipales ConClusiones}

\section{1) CONCLUSIONES FINALES}

El sistema chileno de asignación de facultades y derechos de filiación y de determinación de su contenido no ha evolucionado, como otros ordenamientos jurídicos, hacia un sistema jurídico que establezca facultades y derechos conjuntos para ambos padres. Sin embargo, el Proyecto de Reforma del cuidado personal, a pesar de asignarlo a uno de los padres, no excluye al padre de la relación de filiación. Es así como el sistema propuesto mantiene cierta titularidad de facultades y derechos para el padre no custodio, a través de la corresponsabilidad, y le permite ejercer ciertas facultades y derechos, especificando el contenido de la relación directa y

Civil, y deberá ser subinscrito al margen de la inscripción de nacimiento del hijo dentro de los treinta días subsiguientes a su otorgamiento. Este acuerdo deberá establecer la frecuencia y libertad con que el padre o madre que no tiene el cuidado personal mantendrá una relación directa y regular con los hijos, y podrá revocarse o modificarse cumpliendo las mismas solemnidades.

El cuidado personal compartido es un régimen de vida que procura estimular la corresponsabilidad de ambos padres que viven separados, en la crianza y educación de los hijos comunes, mediante un sistema de residencia que asegure su adecuada estabilidad y continuidad".

75 De este modo, en el Proyecto originario, se proponía el siguiente artículo 40 de la LPM: "Artículo 40.- Para los efectos de los artículos 225, inciso tercero; 229 y 242, inciso segundo del Código Civil, y de otra norma en que se requiera considerar el interés superior del hijo como criterio de decisión, el juez deberá ponderar al menos los siguientes factores:

a) Bienestar que implica para el hijo el cuidado personal del padre o madre, o el establecimiento de un régimen judicial de relación directa, regular y personal, tomando en cuenta sus posibilidades actuales y futuras de entregar al hijo estabilidad educativa y emocional;

b) Riesgos o perjuicios que podrían derivarse para el hijo en caso de adoptarse una decisión o cambio en su situación actual;

c) Efecto probable de cualquier cambio de situación en la vida actual del hijo, y

d) Evaluación del hijo y su opinión, especialmente si ha alcanzado la edad de catorce años”. 
regular. De este modo la relación directa y regular del padre no custodio se separada definitivamente del denominado régimen de visitas. Lamentablemente, era preferible un sistema de asignación del cuidado personal, tanto legal supletorio, como judicial, conjunto y excepcionalmente unilateral. Naturalmente, un sistema excepcional de asignación unilateral, exigiría mantener facultades y derechos para al padre no custodio, conforme al interés superior del niño. Un sistema como este es óptimo por cuanto resuelve dos casos difíciles, y presentes en la realidad chilena. Los padres ausentes no podrían obtener el cuidado personal conjunto, por cuanto en dichos casos el cuidado personal, conforme al interés superior del hijo, sería unilateral; pero además los padres, que quisieren litigar, exigiendo un cuidado personal unilateral, solo lo harán en casos graves en que el interés superior lo amerite. Ello evitaría un exceso de litigación y crearía los incentivos para que los padres se pongan de acuerdo, por cuanto de no ser así será el juez el que les impondrá de igual forma un cuidado compartido.

\section{2) CONCLUSIONES RESPECTO DEL PROYECTO DE REFORMA AL CUI- DADO PERSONAL}

a. Tanto la regla de asignación del cuidado personal judicial, como la regla general de asignación legal supletoria han sido mejoradas en la actual tramitación en el Congreso, sobre todo en el Senado.

b. El que se establezcan facultades y derechos conjuntos, a través de la corresponsabilidad, es muy positivo; pero se aprecia un exceso de figuras relevantes en la asignación de facultades y derechos de filiación. Ello es evidente desde que ni el Proyecto, ni la discusión que se ha llevado a cabo en el Congreso han considerado cómo se relacionan estas figuras con la autoridad parental. Así, después de la reforma tendríamos: la corresponsabilidad de los padres, la autoridad parental, el cuidado personal, la relación directa y regular y, finalmente, la patria potestad.

c. El Proyecto de Reforma otorga el cuidado personal de forma exclusiva a uno de los padres, de acuerdo a los principios del interés superior del niño e igualdad de los padres, conforme a un Derecho de la Infancia, que si bien es moderno, se aleja un tanto de Derecho comparado. Así, se puede apreciar si se compara el sistema propuesto con los vigentes en Italia, el Reino Unido, Estados Unidos de América o España, que exigen en gran medida que el cuidado personal sea conjunto.

d. Sin perjuicio de lo anterior, el sistema propuesto, que establece facultades y derechos conjuntos de filiación, e indistintos para el padre no custodio como regla de asignación judicial, si bien no es óptimo para 
resolver los problemas que el dilema del prisionero plantea, llevará a que los jueces se inclinen por otorgar facultades y derechos que sean socialmente positivos para los hijos, los padres y la sociedad. Pero, la Reforma será socialmente cara por cuanto tensionará a los padres y a los jueces -la propensión a litigar será mayor en el sistema propuesto que en un sistema de cuidado personal conjunto-, sobre todo mientras la jurisprudencia de los tribunales se asiente ${ }^{76}$.

\section{BIBLIOGRAFÍA}

- Acuña San Martín, Marcela (2011): Efectos jurídicos del divorcio. Abeledo Perrot y Thomson Reuters, Santiago de Chile, 474 pp.

- Alessandri Rodríguez, Arturo (1948): "El Código civil chileno y sus reformas", en: RDJ, t. XLV, No 3 y 4 y (2010): en: Doctrinas Esenciales. Derecho Civil. Instituciones Generales, Tavolari Oliveros, Raúl (Director), Editorial Jurídica de Chile, Puntolex y Thomson Reuters.

- Baldijeva, Miglena (2003): The concept of parental responsibility in Bulgarian and English Law. En: Perspectives for the unification and harmonization of Family Law in Europe, intersentia editorial, pp. 402-411.

- Barcia Lehmann, R. (2011): Fundamentos del Derecho de Familia e Infancia, Editorial Thomson, Santiago de Chile, pp. 598.

- Barcia Lehmann, R. (2012): "Una Mirada al Cuidado Personal, y en especial a los artículos 224, 225.1 ${ }^{\circ}$ y $3^{\circ}$ del Código Civil y 42 de la Ley de Protección de Menores, desde la perspectiva del Interés superior del Niño", en: Estudios de Derecho Civil VII (X Jornadas de Derecho Civil), Viña del Mar [Elorriaga De Bonis, Fabián], Abeledo Perrot, LegalPublishing Chile y Thomson Reuters, Santiago de Chile, pp.127 a 145 .

- Barrientos Zamorano, Marcelo, (2012): “¿Es interés superior o inferior del niño. Aplicación jurisprudencial del artículo 42 de la Ley de Menores a la luz del Código Civil”, en: Estudios de Derecho Civil VII (X Jornadas de Derecho Civil), Viña del Mar [Elorriaga De Bonis, Fabián], Abeledo Perrot, LegalPublishing Chile y Thomson Reuters, Santiago de Chile, pp. 117-126.

76 Como se ha puesto de relieve en el presente trabajo ello será especialmente de esta forma en los casos en que la madre venía no respetando las facultades y derechos del padre; pero respecto de los futuros padres el sistema actual permite una suerte de coparentalidad-que si los tribunales se ocupan de aplicarla correctamente- generará los incentivos para que los padres lleguen a acuerdos beneficiosos para la sociedad, ellos mismos y sus hijos. 
- Cardenal, Rafael (2011): “Tema 16. Patria potestad” en: Tomo I. Parte Sustantiva. Los 25 temas más frecuentes en la vida práctica del derecho de familia, Lledó Yagüe, Francisco, Sánchez Sánchez, Alicia (directores), Monje Balmaseda, Óscar (coord.), pp. 435-483.

- Court Murasso, Eduardo (2010): Curso de Derecho de Familia, la Filiación por Naturaleza, Abeledo Perrot, LegalPublishing, Santiago de Chile, 111 pp.

- D. Meyer, David (2005 - 2006). "The constitutional rights of noncustodial parents", en: Hofstra Law Review, pp. 1461-1494.

- De Witt Gregory, John, N. Swisher, Peter y L. Wolf (2005): Sheryl Understanding Family Law, LexisNexis, 503 pp.

- Del Vas González, Juan María (2010): "Rottura de lla famiglia e interesse dei figli en el Derecho Civil italiano" en: Revista Critica de Derecho Inmobiliario, No 717, pp. 209-231.

- Díez-Picazo, L. (1989): "La Figura del Convenio Regulador en el Marco del Negocio Jurídico Familiar y de los Principios Constitucionales del Derecho de Familia”, capítulo I en: Convenios Reguladores de las Crisis Matrimoniales, Instituto de Ciencias para la Familia, Ediciones Universidad de Navarra, S.A., Pamplona, Espańa, pp. 37-44

- Finocchiaro, M. (2006): "Riconosciuto anche alla prole il diritto di frequentare i genitori”, en: Guida al dir.

- Gómez de la Torre, Maricruz (2008): "El nuevo derecho de la niñez", en: Estudios de Derecho Privado, Libro Homenaje al profesor Gonzalo Figueroa Yáñez, Editorial Jurídica de Chile, Santiago de Chile, pp. 435-460.

- Guilarte Martín-Calero, Cristina (2010): “Criterios de atribución de la custodia compartida. A propósito de la línea jurisprudencial iniciada con la Sentencia del Tribunal Supremo de 8 de octubre de 2009" en: InDret, Revista de Análisis del Derecho, Julio, Barcelona, España, pp. 21.

- Lathrop Gómez, Fabiola (2008): Custodia compartida de los hijos, La Ley, Madrid, España, pp. 160.

- Lathrop Gómez, Fabiola (2010): “(In)constitucionalidad de la regla de atribución preferente materna del cuidado personal de los hijos del artículo 225 del código civil chileno" en Revista Ius et Praxis, Año 16, no 2, pp. $147-184$.

- Lathrop, Fabiola (2008): "La custodia alternada o sucesiva de los hijos", en: Estudios de Derecho Privado, Libro Homenaje al profesor Gonzalo Figueroa Yáñez, Editorial Jurídica de Chile, Santiago de Chile, pp. 461-483.

- Linacero de la Fuente, María Asunción (1990): “Acerca de la Posible Inconstitucionalidad del artículo 159 del Código Civil”, 
en: Revista de Derecho Privado, julio-agosto, No 74, Número 7-8 Editorial Revista de Derecho Privado, Madrid, pp. 561-582

- López, A., Montés, V. L. y Roca, E. (1997): Derecho de Familia, Tercera Edición, Valencia, Tirant lo Blanch, pp. 408.

- Morell, Ana (2010): "La posición del tribunal europeo de derechos humanos sobre la custodia compartida de hijos no matrimoniales", en: Revista de Derecho de Familia No 2, Abeledo Perrot, Santiago de Chile, junio, pp. 241-265.

- Obras Completas de Andrés Bello (1981): Tomo XIV, volumen I, Código civil, Casa de Bello, Caracas, Venezuela.

- Ortuño Muñoz, Pascual (2005): Tratado de derecho de Familia, aspectos sustantivos y procesales, Editorial Sepin, Madrid, Espańa, $1458 \mathrm{pp}$.

- Palma Palma, Julieta (s. f.): "Familias adolescentes y jóvenes en Chile: cambios, a sincronías e impactos en sus formas de integración social”, en: Estudios de caso No 108, tesina de magíster en Gestión y Políticas Públicas de la Universidad de Chile, 67 pp.

- Probert, Rebecca (2009): Cretney and Probert's Family Law, School of Law, University of Warwick, Sweet \& Maxwell, England and Wales, 416 pp.

- Rodríguez Pinto, María Sara (2009): "El Cuidado Personal de Niños y Adolescentes en la Familia Separada: Criterios de Resolución de Conflictos de Intereses entre Padres e Hijos en el Nuevo Derecho Chileno de Familia” en: Revista Chilena de Derecho, vol. 36, núm. 3, pp. 545-586.

- Rogerson, Carol (2001): "The Child Support Obligation of Stepparents", en: Canadian Journal of Family Law (Can J. Fam.), Vol. 18, January, pp. 9-158.

- Ruz Lártiga, Gonzalo (2010), "El derecho de visitas en Francia: un derecho de la persona en familia en la búsqueda del justo equilibrio entre derecho parental, interés del niño y prerrogativas de terceros", en: Revista Chilena de Derecho de Familia, Ruz Lártiga, Gonzalo (Director Científico), Abeledo Perrot, LegalPublishing Chile, t. 3, pp. 139-161.

- VAldés S, Ximena (2009) “El lugar que habita el padre en Chile contemporáneo. Estudio de las representaciones sobre la paternidad en distintos grupos sociales", en: Polis, Revista de la Universidad Bolivariana, Universidad de Los Lagos, Vol. 8, No 23, pp. 385-410.

- Weinstein W, Graciela (1999) "Autoridad Paterna y Patria Potestad" en: El Nuevo Estatuto de Filiación en el Código Civil Chileno, Fundación Universidad de Chile, Santiago de Chile, pp. 57-67.

- Zarraluqui Navarro, Elena (2010) Guarda y custodia vs patria potestad en cuanto a las residencia de los hijos menores, Derecho de 
Familia, Novedades en dos perspectivas, Asociación Española de Abogados de Familia, Dykinson, Madrid, España, pp. 139-180.

\section{Sitios VISITADOS}

- http://papers.ssrn.com/sol3/papers.cfm?abstract_id=1300391

- http://www.senado.cl/appsenado/templates/tramitacion/index.php http://www.camera.it/parlam/leggi/06054l.htm

- http://www.thetimes.co.uk/tto/news/uk/article1950995.ece

- http://www.bverfg.de/entscheidungen/rs20100721_1bvr042009en. html

- http://www.bverfg.de/entscheidungen/rs20100721_1bvr042009. html

- http://www.tribunalconstitucional.cl/index.php/sentencias/ download/pdf/1272

\section{NORMAS CITADAS}

- Bürgerliches Gesetzbuch [Código Civil alemán]

- Código Civil chileno

- Código Civil español

- Code [Código Civil francés]

- Codice Civile [Código Civil italiano de1942]

- Constitución Política del Estado de Chile

- Convención de Naciones Unidas sobre Derechos del Niño

- Children Act de 1989

- Ley de Filiación [Ley No 19.585/1998]

- Ley de Matrimonio Civil [Ley No 19.947/2004]

- $\quad$ Ley de Tribunales de Familia [Ley No 19.968/2004]

- Ley de Protección de Menores [Ley No 16.618/2000]

- Leyes No 5.521 de 1934

- $\quad$ Ley No 10.271 de 1952

- $\quad$ Ley No 18.802 